\title{
Biotic controls on shallow translational landslides
}

\author{
Peter Vorpahl, ${ }^{1,4 *}$ Claudia Dislich, ${ }^{2}$ Helmut Elsenbeer, ${ }^{1}$ Michael Märker ${ }^{3}$ and Boris Schröder ${ }^{1,4}$ \\ ${ }^{1}$ University of Potsdam, Institute of Earth and Environmental Sciences, 14476 Potsdam, Germany \\ ${ }^{2}$ Helmholtz Centre for Environmental Research - UFZ, Department of Ecological Modelling, 04318 Leipzig, Germany \\ 3 Heidelberger Akademie der Wissenschaften, c/o Geographisches Institut der Eberhard Karls Universität, Tübingen, Germany \\ ${ }^{4}$ Technische Universität München, Landscape Ecology, Freising-Weihenstephan, Germany
}

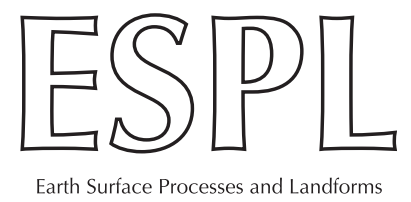

ABSTRACT: In undisturbed tropical montane rainforests massive organic layers accommodate the majority of roots and only a small fraction of roots penetrate the mineral soil. We investigated the contribution of vegetation to slope stability in such environments by modifying a standard model for slope stability to include an organic layer with distinct mechanical properties. The importance of individual model parameters was evaluated using detailed measurements of soil and vegetation properties to reproduce the observed depth of 11 shallow landslides in the Andes of southern Ecuador. By distinguishing mineral soil, organic layer and aboveground biomass, it is shown that in this environment vegetation provides a destabilizing effect mainly due to its contribution to the mass of the organic layer (up to $973 \mathrm{t} \mathrm{ha}^{-1}$ under wet conditions). Sensitivity analysis shows that the destabilizing effect of the mass of soil and vegetation can only be effective on slopes steeper than $37.9^{\circ}$. This situation applies to $36 \%$ of the study area. Thus, on the steep slopes of this megadiverse ecosystem, the mass of the growing forest promotes landsliding, which in turn promotes a new cycle of succession. This feedback mechanism is worth consideration in further investigations of the impact of landslides on plant diversity in similar environments. Copyright (c) 2012 John Wiley \& Sons, Ltd.

KEYWORDS: shallow translational landslides; tropical montane forest; biomass; organic layer

\section{Introduction}

Apart from their hazardousness for human life and infrastructure, landslides can provide a a beneficial ecological effect: in tropical montane rainforests, landslides represent one of the most important ecosystem disturbances (Lozano et al., 2005; Köhler and Huth, 2007; Bussmann et al., 2008). Their size and frequency contribute to the high levels of vascular plant diversity in these areas, since landslide scars provide habitats for pioneer species (Connell, 1978; Sheil and Burslem, 2003). From an ecological point of view, knowledge on the driving mechanisms of landslides is a prerequisite for understanding and predicting potential future changes in the general conditions for biodiversity in tropical montane ecosystems. This can guide the planning of conservation measures. To counteract the threat landslides represent for human activity and to provide tools for planning of sustainable infrastructure measures, the prediction of the spatial occurrence probability of landslides has turned into a major research effort (e.g. Montgomery and Dietrich, 1994; Wu and Sidle, 1995; Guzzetti et al., 1999; Guzzetti, 2004; Guitierres et al., 2010; Vorpahl et al., 2012).

The conceptual abstraction underlying most process-based models of shallow translational landslides is that of an infinite slope segment covered with vegetation (Wu et al., 1979; Buchanan and Savigny, 1990; Sidle and Wu, 1999). Mohr-Coulomb's failure criterion prescribes that the factor of safety (FoS) for a slope segment is given by the ratio of stabilizing and destabilizing forces, where $\mathrm{FoS}<1$ indicates unstable conditions:

$$
\text { FoS }=\frac{\text { Stabilizing forces }}{\text { Destabilizing forces }}
$$

Most implementations of this concept include stabilizing effects of vegetation by an increase of soil cohesion due to root networks. As a consequence, the stabilizing effect of roots of different plant species has been subject to field experiments (Wu et al., 1988a; Abernethy and Rutherfurd, 2001; van Beek et al., 2005) and laboratory tests (Wu et al., 1988b; De Baets et al., 2008). These experiments provided insights for slope stability models that, for example, made it possible to investigate the influence of different forms of land use on landslide distribution and frequency (Schmidt et al., 2001; Sidle and Dhakal, 2003). Other investigations also considered the influence of vegetation on slope hydrology (Collison and Anderson, 1996; Keim and Skaugset, 2003). In contrast, the destabilizing effects of vegetation biomass or the effect of wind forces as transferred by trees into the ground via a turning moment (Sidle and Ochiai, 2006) are assumed to be outweighed by the contribution of roots to soil cohesion (O'Loughlin, 1974) and are neglected in most studies.

Neglecting the destabilizing effects of vegetation, however, is presumably not appropriate everywhere. We suspect that in our study area in the tropical montane rainforest in the Andes of southern Ecuador (Figure 1) vegetation plays an important role for slope stability by causing a cyclic change of slope stabilization due to root networks and an increasingly destabilizing effect of the mass of a growing forest. The latter comprises 


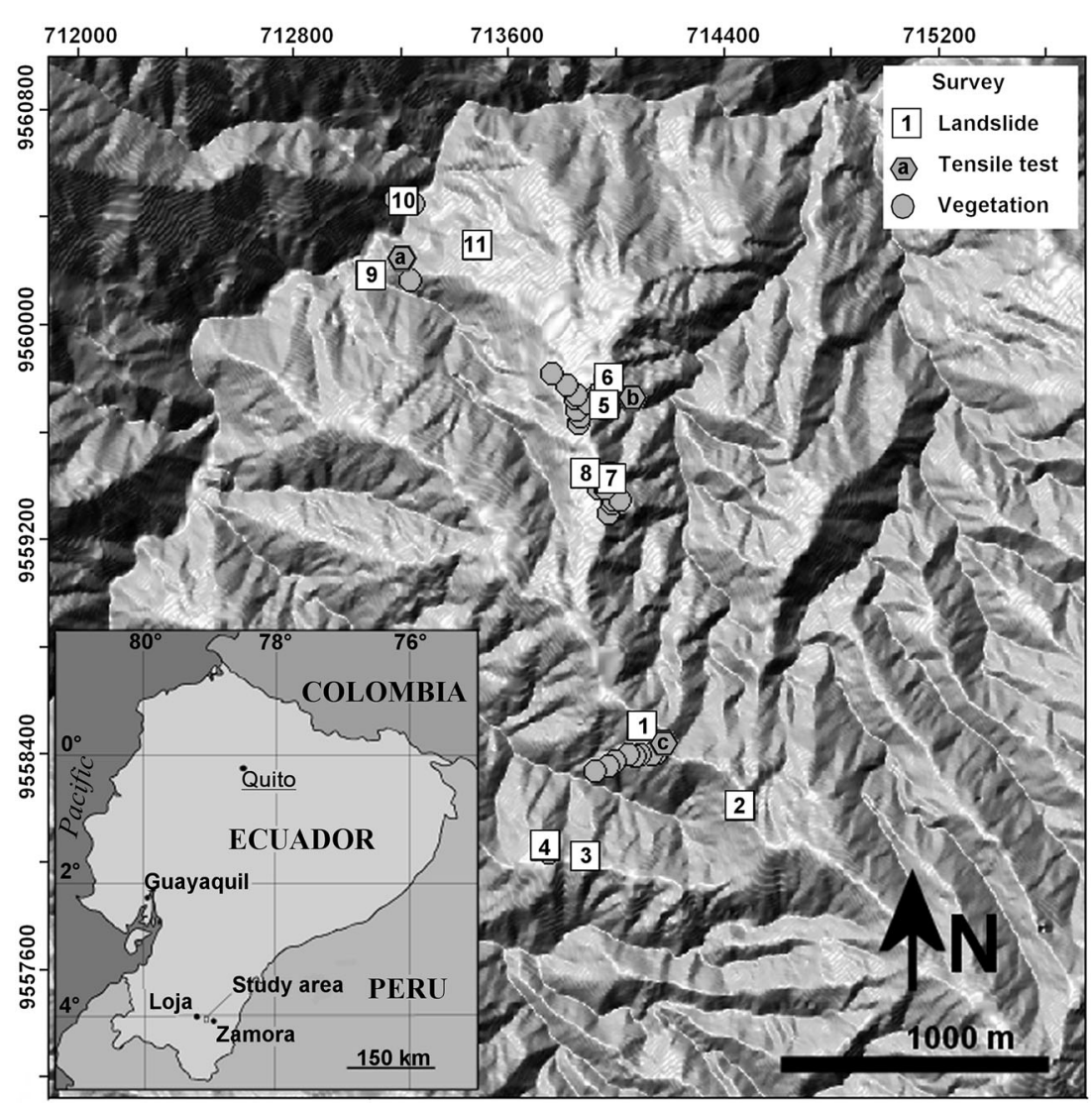

Figure 1. Location of the study area in southern Ecuador, east of Loja. Eleven investigated landslides are marked by numbered rectangles, surveys of vegetation-related parameters by circles and locations of organic layer tensile resistance measurements by hexagons. Annotated UTM-WGS84 coordinates.

above-ground biomass as well as the mass of a thick organic layer above the mineral soil mainly consisting of dead organic matter woven with plant roots (Wilcke et al., 2002). Thus, in this mountainous ecosystem, a dynamic feedback between vegetation succession, slope stability and landsliding is likely (Richter et al., 2009; Muenchow et al., 2012). The degree to which vegetation possibly affects slope stability, however, remains unknown.

The main objective of this paper, therefore, was to quantify the effects of vegetation on slope stability. In an earlier study (Vorpahl et al., 2012) we used a statistical approach to deduce driving factors of landslides in the study area from terrain attributes inferred from a digital terrain model. In the absence of direct information on vegetation related parameters, a relation of vegetation and landslide occurrence probability could only be inferred from general gradients in vegetation structure (cf. Soethe et al., 2006a, 2006b; Leuschner et al., 2007; Moser et al., 2008; Oesker et al., 2008) that corresponded to some of the terrain attributes used in that study. Thus, in this study, we focused on a process-based approach that directly accounts for vegetation while distinguishing the effects of above-ground biomass and the mass of the organic layer.

For this purpose, we modified a standard model for shallow slope stability to incorporate a thick organic layer on top of the mineral soil. Prandini et al. (1977) pointed out that the assumption of roots growing into the mineral soil and enhancing its mechanical properties does not apply universally. It is unlikely to apply in ecosystems in which tree roots preferentially explore massive organic layers rather than the underlying mineral soil. Thus we treated the organic layer and the mineral soil as separate layers with distinct mechanical properties, loosely connected by a fraction of roots anchoring the organic layer in the mineral soil.
Assuming that the situation close to a landslide reflects the situation on the landslide before the event, we applied the model to measurements conducted on and close to 11 landslides in the study area (Figure 1). Using the model to reproduce the observed landslide depths, we completed a sensitivity analysis and explored the influence of single-model parameters on slope stability. Using this sensitivity analysis, we assess the circumstances under which vegetation can destabilize a slope and ask whether the destabilizing effects of vegetation are outweighed by stabilizing effects, as is often assumed (O'Loughlin, 1974).

\section{Study Area}

The data used here were collected in the Reserva Biósfera de San Francisco, part of the biosphere reserve Podocarpus - El Condor in the Andes of southern Ecuador ( $3^{\circ} 58^{\prime} \mathrm{S}, 79^{\circ} 04^{\prime} \mathrm{W}$, Figure 1 ). The study area consists of several low-order catchments south of Rio San Francisco and comprises $8.4 \mathrm{~km}^{2}$ ranging in elevation from 1870 to $3165 \mathrm{~m}$ above sea level (a.s.I.). Steep slopes (up to $\left.70^{\circ}\right)$ are covered by an evergreen lower $(<2150 \mathrm{~m}$ a.s.l.) and upper broad-leaved montane rainforest up to the tree line between 2700 and $3000 \mathrm{~m}$ a.s.l. At higher elevations, a subpáramo shrubland emerges (Beck et al., 2008).

In this mountainous ecosystem, shallow translational landslides are a frequent, natural phenomenon (Lozano et al., 2005; Bussmann et al., 2008; Dislich et al., 2009; Restrepo et al., 2009; Richter et al., 2009). Visible landslide scars permanently cover approximately $1-3 \%$ of the study area, as deduced from aerial photographs (taken in 1962, 1969, 1976, 1989 and 1998, respectively; Stoyan, 2000). Most landslides within the study area can be classified as rockslides, earthflows and shallow translational landslides. Rockslides and earth flows occur close to 
anthropogenic influences (such as roads), while within the anthropogenically undisturbed parts of the area all rapid mass movements have been classified as shallow translational landslides (Bussmann et al., 2008).

In addition to this, massive organic layers above the mineral soil exist that mainly consist of dead organic matter woven with plant roots, while containing only very small amounts of mineral soil. We found these layers, the mass of which may reach $700 \mathrm{t} \mathrm{ha}^{-1}$ (Wilcke et al., 2002), preferentially on steep slopes in the intermediate altitudinal ranges within the study area (2100-2700 m a.s.I.).

\section{Field Investigations}

During three field campaigns from September 2008 to November 2010, we investigated a total of 11 landslides in the study area (numbered rectangles in Figure 1). Soil physical parameters, such as in situ and dry soil bulk density $\left(\rho_{\mathrm{s}}\right)$, water content $(\Theta)$, soil cohesion $\left(C_{\mathrm{s}}\right)$ and internal angle of friction $(\phi)$ were assessed in soil profiles, which were excavated atthe top edges of 10 landslides. We assessed vegetation-related parameters, such as above-ground biomass $\left(M_{B}\right)$ and organic layer thickness $\left(h_{\mathrm{O}}\right.$, circles in Figure 1$)$ and measured the organic layer's cohesion $\left(C_{O}\right.$, hexagons in Figure 1$)$. Geographic coordinates as well as altitude above sea level were recorded in UTM WGS84 format with the aid of a hand-held GPS device of type Garmin eTrex Vista $\mathrm{HCx}$ with an integrated barometric altimeter.

\section{Landslide surveys}

We classified landslides into 'fresh' for those without vegetation on their scar and 'old' for others, because an exact determination of landslide age was not possible from the successional state of the vegetation, and aerial photographs only enabled a rough classification. With the aid of a total station, as well as by manual measurements with compass, clinometer and tape measure, relative $3 \mathrm{D}$ coordinates of approximately 100 points on each landslide were recorded. These points served as a data source for a three-dimensional reconstruction of the failure plane from which topographic information, such as landslide lengths $(L)$ and median widths $(W)$, were derived by projection onto a horizontal plane. Average slope angles $(\alpha)$ were calculated by a linear regression through a projection of all points onto a vertical plane.

Soil bulk densities $\left(\rho_{s}\right)$ and in situ soil water content $(\Theta)$ were calculated from undisturbed soil samples, taken at different depths within the soil profiles, which were dug at the top edges of 10 of the 11 landslides. Where possible, we took three samples per soil layer, which were weighed, dried $\left(24 \mathrm{~h}\right.$ at $\left.80^{\circ} \mathrm{C}\right)$, and weighted again. According to Jahn et al. (2006), we conducted field assessments of soil texture and soil skeleton in all soil horizons. Landslide depths $\left(h_{\mathrm{s}}\right)$ were estimated by visually fixing the intersection of the landslide surface with the vertical soil profile.

Soil cohesion was measured in situ using a Geonor H-60 handheld vane tester three times per identifiable soil layer within each profile. The method of measuring soil shear resistance with a small torsion probe (like the Geonor $\mathrm{H}-60$ ) tends to overestimate soil cohesion, if the soil contains skeleton. This was the case in our soil profiles, where soil textures ranged from clay over silty sand to fine sand, while the particle size of the coarse soil skeleton ranged from millimetres to decimetres in diameter. Nonetheless, the vane tester is easily applied and it is useful to gain insights into the spatial variability and in the general magnitude of soil cohesion.
We assessed the internal angle of friction by repeated field shear box experiments under different loads. This approach follows a common method for in situ measurement of soil shear resistance (cf. Wu et al., 1988a; Comino and Duretta, 2009) but uses a much smaller device. A steel cylinder $(d=72 \mathrm{~mm})$ was used to horizontally shear out an undisturbed soil sample, while measuring the maximum force applied by a spring balance with a drag indicator (Figure 2). Different vertical loads were superimposed to the soil in the cylinder by a forcer, whose diameter was slightly smaller than the inner diameter of the cylinder. The forcer was attached to the bottom of a bucket, making it possible to vary the superimposed load. This procedure was repeated at least twice per superimposed load and with at least two different loads.

After Mohr-Coulomb, the soil's shear resistance results from a normal load applied to the soil and the soil cohesion:

$$
\tau=\sigma \tan \phi+C_{\mathrm{s}}
$$

Where $\tau$ is the shear resistance $\left[\mathrm{N} \mathrm{m}^{-2}\right], \sigma$ is the normal load $\left[\mathrm{N} \mathrm{m}^{-2}\right], \phi$ is the internal angle of friction and $C_{\mathrm{s}}$ is the soil cohesion $\left[\mathrm{N} \mathrm{m}^{-2}\right.$ ]

Thus a linear regression through all measurements is used to determine the soil's internal angle of friction $(\phi)$ and its cohesion $\left(C_{\mathrm{s}}\right)$ :

$$
\frac{F_{\text {shear }}}{r^{2} \pi}=\frac{F_{\text {load }}}{r^{2} \pi} \tan \phi+C_{\mathrm{s}}
$$

where $F_{\text {shear }}$ is the applied maximum force to shear out the probing cylinder $(\mathrm{N}), r$ is the radius of the probing cylinder (m) and $F_{\text {load }}$ is the additional weight force applied to the soil in the probing cylinder $(\mathrm{N})$.

Even if the measurements of $C_{\mathrm{s}}$ systematically overestimate soil cohesion, the results obtained for the internal friction angle $(\phi)$ should not be affected. The field shear box is still sensitive to coarse stones in the sample. Thus we were able to use it on seven of the 11 landslides (i.e. \#1, \#2, \#5, \#6, \#7, \#9 and \#11 in Figure 1). On four of those seven landslides (i.e. \#2, \#5, \#6, \#7 in Figure 1), we applied the method in the soil profile close to the estimated depth of failure. On two others (\#1 and \#9 in Figure 1), we were able to apply the method at different depths of the soil profile and on the oldest landslide (i.e. \#11 in Figure 1) we conducted measurements on the surface itself.

\section{Vegetation-related parameters}

In the absence of knowledge about the real situation preceding a sliding event, we investigated vegetation-related parameters close to landslides, assuming that the situation there is similar to that on the site before the event. Standard approaches to assess aboveground biomass require surveys in homogeneous

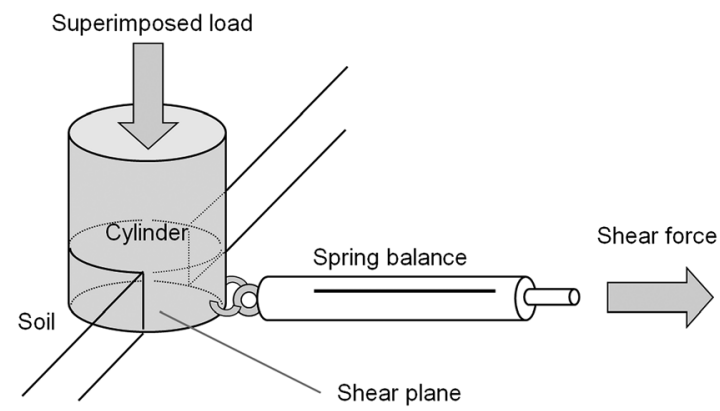

Figure 2. Device for measuring soil shear resistance under different loads 
forest stands of at least $1 \mathrm{ha}(100 \mathrm{~m} \times 100 \mathrm{~m})$ in extent (Brown et al., 1989; Brown, 1997; Leuschner et al., 2007). Shallow translational landslides in the study area, however, are initiated at a smaller scale (widths ranging from 10 to $30 \mathrm{~m}$ ). Thus we were interested in possible local biomass aggregations at this scale and assessed vegetation biomass and vertical thickness of the organic layer in circular areas, with a radius of $5 \mathrm{~m}$ around several single points close to landslides (point investigations, circles in Figure 1). Since our measurements were made on steep slopes, we additionally measured the upslope and downslope slope angle $(\alpha)$ using a clinometer.

For all the trees within the sample circle (radius $=5 \mathrm{~m}$ ) we estimated above-ground dry tree biomass density. Therefore, we calculated stem diameters at breast height $(\mathrm{DBH}, 1.3 \mathrm{~m})$ from stem perimeters, measured using a tape measure. Following Leuschner et al. (2007), we applied an allometric equation for the estimation of average tree biomass, which, after Brown (1997), is suitable for American tropical wet forests:

$$
M_{\mathrm{t}}=21.297-6.953 \mathrm{DBH}+0.740 \mathrm{DBH}^{2}
$$

where $M_{\mathrm{t}}$ is the dry biomass per tree $(\mathrm{kg})$ and $\mathrm{DBH}$ is the stem diameter at breast height $(130 \mathrm{~cm})(\mathrm{cm})$.

The above-ground biomass density was then calculated by summing all tree masses obtained by one-point investigation, divided by the investigated area, projected onto a horizontal plane:

$$
\mathrm{MB}=\frac{\sum_{i=1}^{n} M_{\mathrm{t} i}}{\pi r^{2} \cos \alpha}
$$

where $\mathrm{MB}$ is the dry biomass density $\left(\mathrm{kg} \mathrm{m}^{-2}\right), n$ is the number of trees in the circle, $\alpha$ is the slope angle $\left(^{\circ}\right)$ and $r$ is the radius of the investigated area $(\mathrm{m})$.

The above-ground biomass density (Equations (4) and (5)) relates to dry matter, while for slope stability analyses we were interested in the fresh biomass. Considering an average wood density of $\rho_{\text {wood }}=600 \mathrm{~kg} \mathrm{~m}^{-3}$, which, after Brown (1997), is an appropriate average value for tropical montane forests and a water content of $26 \%$ up to $88 \%$ (Suzuki, 1999; Nogueira et al., 2008), we assume that the density of fresh wood roughly exceeds that of dry wood by a factor of two. Thus we used the doubled values in our stability calculations.

Owing to natural spatial heterogeneity of forests and the relatively small survey area $\left(78.5 \mathrm{~m}^{2}\right.$ per site) we expected our results to vary strongly between sites. Besides, in the study area, above-ground biomass decreases with altitude (Leuschner et al., 2007; Moser et al., 2008). Therefore we used a linear regression on biomass measurements at different altitudes to both reproduce this decrease and estimate ranges for the landslides we investigated.

\section{Organic layer properties}

Within each $5 \mathrm{~m}$ diameter sample circle up to 20 measurements of vertical organic layer thickness were obtained by vertically probing the layer with a pole at different random locations. Using slope angle measurements, we then calculated organic layer thickness perpendicular to the slope $\left(h_{0}\right)$.

In order to estimate organic layer bulk densities, 64 samples were taken at five different locations in the study area (close to landslides \#4 and \#5 in Figure 1 at an altitude of $2300 \mathrm{~m}$ a.s. I.) by excavating rectangular blocks $(0.3 \mathrm{~m} \times 0.3 \mathrm{~m})$ through the complete organic layer down to the mineral soil and measuring their volume. The excavated organic layer material was weighed in situ. Fifteen samples (three per location) were saturated with water and weighed again in order to estimate the maximum organic layer bulk density under rainfall conditions.

We assessed organic layer cohesion in situ close to landslides (hexagons in Figure 1$)$ by repeated application $(n=903)$ of rupture tests. Organic layer rupture tests were conducted in vertical profiles through the organic layer, starting at the top of the profile and were subsequently executed down to the mineral soil (see Figure 3).

Each rupture test started with the preparation of a block of organic layer material of reproducible size $(0.1 \mathrm{~m} \times 0.1 \mathrm{~m})$ by sawing two vertical, parallel cuts. A small rake served as a gripper and was hooked into the material from above in such a way that it covered a depth of $0.1 \mathrm{~m}$. While horizontally pulling out the specimen, we measured necessary forces with a spring balance equipped with a drag indicator. We assumed the rupture plane to follow roughly a circular path with a radius of $10 \mathrm{~cm}$ (Figure 3) and calculated its area as $0.0157 \mathrm{~m}^{2}$. While conducting tests at different depth within the organic layer, we distinguished between measurements in the layer and at the boundary to the mineral soil. We observed that roots were untangled from the root mat rather than torn apart, so that larger roots affect a larger volume of the organic layer, affecting our estimate of the hypothetical rupture plane. Following De Baets et al. (2008), a large number of fine roots contribute more to the total tensile resistance than a small number of large roots. Thus we measured the tensile resistance of the fine root matrix in the organic layer, not considering plant roots with diameters significantly greater than $5 \mathrm{~mm}$, which we encountered in less than $0.5 \%$ of the specimens. Expecting high variations in root resistance, we conducted up to 100 repetitions per profile.

\section{Model}

Following Gabet and Dunne (2002) and Casadei et al. (2003), we idealize a slope failure by a shallow, rectangular block on an inclined plane (Figure 4). The destabilizing force results from the downhill component of the block's weight force, while the block is stabilized by shear resistance at its basal plane and at the sides and by tensile resistance at the upper perimeter.

A shallow slope stability model that includes lateral forces implicitly violates the infinite slope assumption since it is sensitive to the failure dimensions. Thus we respect these dimensions in our model, namely by the slope-parallel length $(L)$ and width $(W)$ of the failure. Organic layer and mineral soil thickness $\left(h_{\mathrm{o}}\right.$ and $\left.h_{\mathrm{s}}\right)$ are measured perpendicular to the slope.

During field surveys, we found massive organic layers which did not contain obvious quantities of mineral soil. Usually the transition to the underlying mineral soil was very sharp and

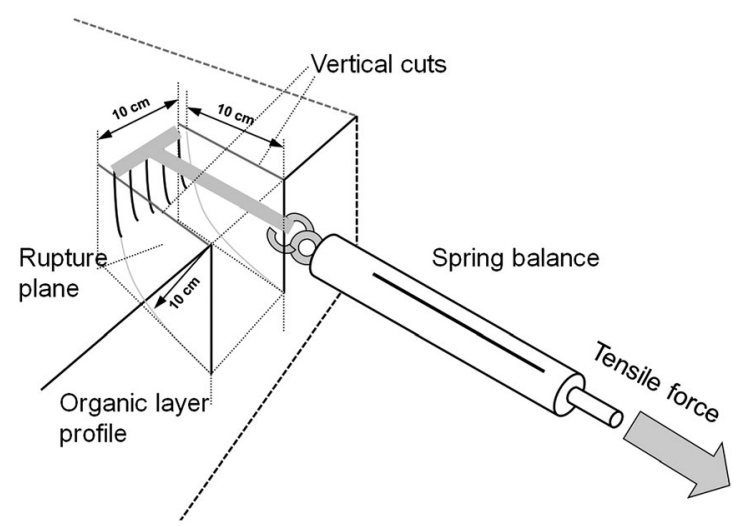

Figure 3. Organic layer rupture test. 


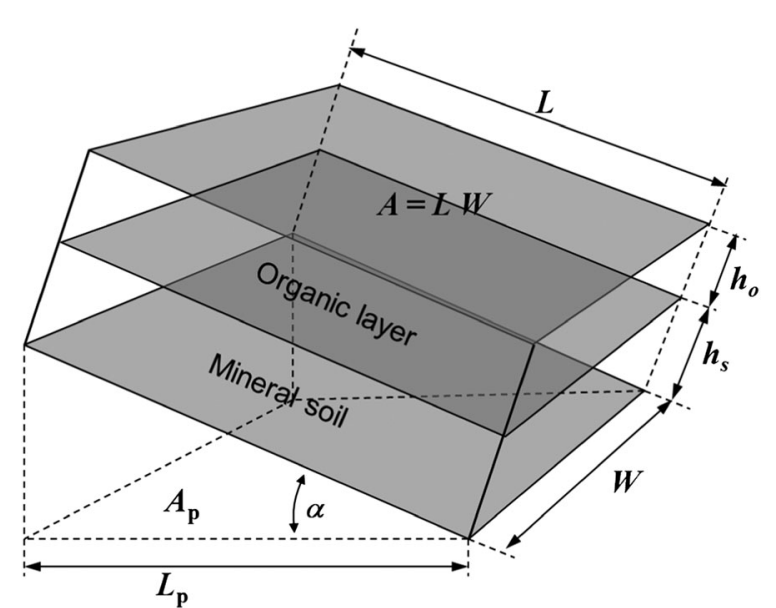

Figure 4. Mechanical setup of the conceptual model. Slope-parallel length $(L)$ and width $(W)$ of the sliding block; $h_{\mathrm{s}}$, height of mineral soil; $h_{\mathrm{O}}$, thickness of organic layer.

the number of roots we found in the uppermost layer of the mineral soil was negligible. Thus the mechanical setup consists of two, non-overlapping layers (Figure 4), which are assumed to be homogeneous. An overlap between these layers, indicating a rooting depth, would not change the mathematical description. By mechanically decoupling the two layers we are able to describe even very shallow translational slides that involve no mineral soil.

The factor of safety is the ratio of stabilizing and destabilizing forces:

$$
\mathrm{FoS}=\frac{F_{\mathrm{b}}+F_{\mathrm{l}}}{F_{\mathrm{G}} \sin \alpha}
$$

where FoS is the factor of safety, $F_{\mathrm{b}}$ is the basal resistance force $(\mathrm{N}), F_{\mathrm{l}}$ is the lateral resistance force $(\mathrm{N}), F_{\mathrm{G}}$ is the block's total weight force $(\mathrm{N})$ and $\alpha$ the slope angle $\left(^{\circ}\right)$.

We were especially interested in the contribution of vegetation to slope stability. This includes above-ground biomass and the mass of roots and dead organic matter in the organic layer. Thus the system's total weight force comprises aboveground biomass, the mass of the organic layer and the mass of mineral soil down to the depth of failure:

$$
F_{\mathrm{G}}=G L W
$$

with

$$
G=\left(\mathrm{MB}+h_{\mathrm{o}} \rho_{\mathrm{o}}+h_{\mathrm{s}} \rho_{\mathrm{s}}\right) g
$$

where $G$ is the weight force per area $\left(\mathrm{N} \mathrm{m}^{-2}\right), g$ is the Earth's acceleration $\left(\mathrm{m} \mathrm{s}^{-2}\right), \mathrm{MB}$ is the above-ground biomass density $\left(\mathrm{kg} \mathrm{m}^{-2}\right), h_{\mathrm{o}}$ is the thickness of the organic layer perpendicular to the slope $(\mathrm{m}), \rho_{\mathrm{o}}$ is the bulk density of the organic layer $\left(\mathrm{kg} \mathrm{m}^{-3}\right), h_{\mathrm{s}}$ is the thickness of the mineral soil perpendicular to the slope $(\mathrm{m})$ and $\rho_{\mathrm{s}}$ is the bulk density of soil $\left(\mathrm{kg} \mathrm{m}^{-3}\right)$.

As prescribed by Mohr-Coulomb's failure criterion, the resistance force in the basal area of the block results from internal friction, soil cohesion and the cohesion provided by roots that penetrate the basal plane. We did not find many torn roots on the slip surfaces of the landslides. Thus we assume the additional root cohesion at the slip surface to be a fraction of the maximum cohesion, as present in the organic layer. In most cases, this fraction can be assumed to be zero:

$$
F_{\mathrm{b}}=F_{\mathrm{N}} \tan \phi+L W\left(C_{\mathrm{s}}+x C_{\mathrm{o}}\right)
$$

where $F_{\mathrm{N}}$ is the effective normal component of the block's weight force $(\mathrm{N}), \phi$ is the internal friction angle of the soil $\left({ }^{\circ}\right)$, $C_{\mathrm{s}}$ is soil cohesion $\left(\mathrm{N} \mathrm{m}^{-2}\right), C_{\mathrm{O}}$ is the organic layer cohesion $\left(\mathrm{N} \mathrm{m}^{-2}\right), x$ is the fraction of roots contributing to basal cohesion and $\alpha$ is the slope angle $\left(^{\circ}\right)$.

The saturated fraction of the vertical soil column causes a hydrostatic pressure at the basal plane. We observed runoff through tubular flow paths and did not see perched water tables at the bottom of the organic layer, even during heavy rain events. Therefore, we assume the organic layer to remain unsaturated under most conditions and take a simplifying approach by assuming that the water table only reaches up to the boundary of the mineral soil and organic layer. By assuming hydrostatic instead of steady flow conditions (Gabet and Dunne, 2002; Casadei et al., 2003), our approach possibly overestimates the hydraulic head. Being interested in a worst-case scenario and considering low soil hydraulic conductivity (Zimmermann and Elsenbeer, 2008), we think this approach is reasonable:

$$
U=\rho_{\mathrm{w}} \frac{m h_{\mathrm{s}}}{\cos \alpha} g
$$

where $U$ is the hydrostatic pressure at the failure plane $\left(\mathrm{N} \mathrm{m}^{-2}\right), m$ is the saturated fraction of the mineral soil column and $\rho_{\mathrm{w}}$ is the bulk density of water $\left(\mathrm{kg} \mathrm{m}^{-3}\right)$. A saturation reaching up into the organic layer, however, can be easily described by allowing for values of $m>1$ or by substituting $m=m^{\prime} \frac{h_{\mathrm{s}}+h_{\mathrm{o}}}{h_{\mathrm{s}}}$, where $m^{\prime}$ is the saturated fraction of the complete soil column.

Thus the effective normal force comprises the normal component of the block's total weight force reduced by pore water pressure acting in and perpendicular to the basal plane:

$$
F_{\mathrm{N}}=(G \cos \alpha-U) L W
$$

$$
F_{\mathrm{N}}=\left[\left(\mathrm{MB}+h_{\mathrm{o}} \rho_{\mathrm{o}}+h_{\mathrm{s}} \rho_{\mathrm{s}}\right) \cos \alpha-\rho_{\mathrm{w}} \frac{m h_{\mathrm{s}}}{\cos \alpha}\right] g L W
$$

The laterally stabilizing force results from soil cohesion and from the organic layer's cohesion. It is effective at both sides and at the upper perimeter of the block:

$$
F_{\mathrm{l}}=(2 L+W)\left(h_{\mathrm{s}} C_{\mathrm{s}}+h_{\mathrm{o}} C_{\mathrm{o}}\right)
$$

Substituting $F_{\mathrm{G}}, F_{1}$ and $F_{\mathrm{b}}$ into Equation (6) leads to the final representation of the factor of safety:

$$
\mathrm{FoS}=\frac{(G \cos \alpha-U) \tan \phi+C_{\mathrm{s}}+x C_{\mathrm{o}}+\frac{2 L+W}{L W}\left(h_{\mathrm{s}} C_{\mathrm{s}}+h_{\mathrm{o}} C_{\mathrm{o}}\right)}{G \sin \alpha}
$$

$$
\mathrm{FoS}=\frac{\left[\left(\mathrm{MB}+h_{\mathrm{o}} \rho_{\mathrm{o}}+h_{\mathrm{s}} \rho_{\mathrm{s}}\right) \cos \alpha-\rho_{\mathrm{w}} \frac{m h_{\mathrm{s}}}{\cos \alpha}\right] \operatorname{gtan} \phi+C_{\mathrm{s}}+x C_{\mathrm{o}}+\frac{2 L+W}{L W}\left(h_{\mathrm{s}} C_{\mathrm{s}}+h_{\mathrm{o}} C_{\mathrm{o}}\right)}{\left(M_{B}+h_{\mathrm{o}} \rho_{\mathrm{o}}+h_{\mathrm{s}} \rho_{\mathrm{s}}\right) g \sin \alpha}
$$


As can be seen, soil cohesion $\left(C_{\mathrm{s}}\right)$, internal friction $(\tan \phi)$ and organic layer cohesion $\left(C_{\mathrm{o}}\right)$ always act as stabilizing components, while the weight load caused by the mass of soil, organic layer and vegetation $(G)$ has an ambiguous effect. By generating shear stress in the basal plane $(G \sin \alpha)$ it destabilizes the slope. At the same time, this total weight acts as a stabilizer by causing static friction due to the normal component $G \cos \alpha$. The stabilizing effect of $G$, however, is reduced by pore water pressure $(U)$ at the basal plane. Normal load $(G \cos \alpha)$, shear stress $(G \sin \alpha)$ and pore water pressure $(U)$ have in common that they all depend on soil thickness $\left(h_{\mathrm{s}}\right)$ and on slope angle $(\alpha)$. We expect the stabilizing effects to be dominant at low slope angles, while on steeper slopes the destabilizing effects gain importance. The role of vegetation is even more ambiguous, since apart from contributing to $G$, it stabilizes the slope by providing additional cohesion at the basal plane and at the sides.

\section{Model application and sensitivity analysis}

To gain insight into the contribution of single-model components to slope stability on the investigated landslides, we followed a stepwise approach. Field measurements of soil cohesion and internal friction angle may not accurately reflect the strength of the residual soils examined (Anderson and Howes, 1985). Thus, as a first step, we back-calculated ranges of soil shear strength that would be necessary for failure. For this purpose we set the factor of safety (Equation (14)) to one and solved the equation for $C_{\mathrm{s}}$ :

$$
C_{\mathrm{s}}^{\text {crit. }}=\frac{G \sin \alpha-(G \cos \alpha-U) \tan \phi-\frac{2 L+W}{L W} h_{\mathrm{o}} C_{\mathrm{o}}-x C_{\mathrm{o}}}{1+\frac{2 L+W}{L W} h_{\mathrm{s}}}
$$

Based upon our measurements and associated uncertainties, we estimated distributions for all model parameters and performed a 10000 -fold Monte Carlo simulation to propagate these uncertainties through the model. Assuming a most unstable situation as given by complete saturation of the mineral soil $(m=1)$,

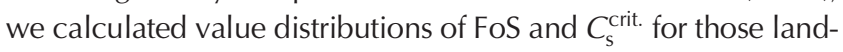
slides where we measured the complete set of parameters. After combining all Monte Carlo results we obtained for $C_{\mathrm{s}}^{\text {crit. }}$ we estimated a plausible value range for soil shear resistance at the time of failure by calculating the mean and standard error of the resulting distribution.

As a second step, we used the back-calculated distribution of $C_{\mathrm{s}}$ to reproduce the observed depth of each landslide (in terms of $h_{\mathrm{s}}$ ) by calculating distributions for the minimum critical soil thickness ( $h_{\mathrm{s}}^{\text {crit. }}$ ) that would be necessary for failure. For this purpose, we set the factor of safety (Equation (15)) to one and solved the equation for $h_{\mathrm{s}}$ :

$h_{\mathrm{s}}^{\text {crit. }}=\frac{\left(\mathrm{MB}+h_{\mathrm{o}} \rho_{\mathrm{o}}\right) g(\cos \alpha \tan \phi-\sin \alpha)+C_{\mathrm{s}}+x C_{\mathrm{o}}+h_{\mathrm{o}} C_{\mathrm{o}} \frac{2 L+W}{L W}}{\left[\frac{m \rho_{\mathrm{w}}}{\cos \alpha} \tan \phi+\rho_{\mathrm{s}}(\sin \alpha-\cos \alpha \tan \phi)\right] g-C_{\mathrm{s}} \frac{2 L+W}{L W}}$

Again, we applied a 10 000-fold Monte Carlo simulation considering all parameter uncertainties. By comparing calculated value ranges of $h_{\mathrm{s}}^{\text {crit. }}$ to the observed depth of failure $\left(h_{\mathrm{s}}\right)$, it is possible to judge whether the model underestimates or overestimates slope stability on each landslide.

Third, we quantified the contribution of each parameter to slope stability on all landslides by carrying out a sensitivity analysis on $h_{\mathrm{s}}^{\text {crit. }}$ (Equation (17)). By varying each parameter in the range of its uncertainty (mean \pm standard error of mean) while all other parameters were held fixed at their mean value, we obtained the absolute contribution of this parameter to prediction uncertainty:

$$
\Delta h_{\mathrm{s}}^{\text {crit. }} X=\left|h_{\mathrm{s}}^{\text {crit. }} X=\bar{X}+\operatorname{err}(X)-h_{s}^{\text {crit. }} X=\bar{X}-\operatorname{err}(X)\right|
$$

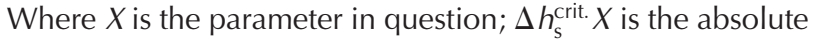
variation in $h_{\mathrm{s}}^{\text {crit. }}$, as caused by the uncertainty of $X(\mathrm{~m}), \bar{X}$ is the mean value of the distribution of $X$ and $\operatorname{err}(X)$ is the uncertainty of $X$ in terms of the standard error of the mean.

To further compare the influences of all parameters on slope stability, we calculated the relative sensitivity of $h_{\mathrm{s}}^{\text {crit. }}$ to parameter variations in the range of $\pm 0.5 \%$ around its observed mean, while all other parameters were held fixed at their observed mean:

$$
S_{X}=\frac{h_{\mathrm{s}}^{\text {crit. }} X=\bar{X} * 1.005-h_{\mathrm{s}}^{\text {crit. }} X=\bar{X} * 0.995}{h_{\mathrm{s}}^{\text {crit. }} X=\bar{X}} \cdot 100 \%
$$

Where $S_{X}$ is the relative sensitivity of $h_{\mathrm{s}}^{\text {crit. }}$ to a $1 \%$ change of $X$ (\%).

The relative sensitivity $\left(S_{X}\right)$ basically allows for a qualitative comparison of the influence of different parameters. It is positive for parameters that have a stabilizing effect (i.e. positive correlation with $h_{\mathrm{s}}^{\text {crit. }}$ ) and negative for parameters that have a destabilizing effect (negative correlation). It also makes it possible to quantitatively compare the influence of the same parameter on different landslides. Using the results of the sensitivity analysis, we discuss the prerequisites for failure on the landslides.

We expected the stabilizing effects of parameters that contribute to the weight load $(G)$ to be dominant at low slope angles, while on steeper slopes their destabilizing effects gain importance. Thus, finally, we identified the degree to which the prerequisites for a destabilizing effect of weight load were fulfilled in the study area and give a quantitative statement on the contribution of vegetation to slope stability.

\section{Results and Discussion}

Planar landslide lengths $\left(L_{\mathrm{p}}\right)$ varied between 7 and $62 \mathrm{~m}$, median widths $(W$ ) ranged from 8 to $23 \mathrm{~m}$ and average slope angles $(\alpha)$ varied between $31^{\circ}$ and $55^{\circ}$ (Table I). Landslide depths $\left(h_{\mathrm{s}}\right)$ ranged from below 0.1 up to $1.3 \mathrm{~m}$ (Table I); two of the landslides (\#4 and \#5) were extremely shallow and one landslide (\#8) exposed a depth of failure of about $0.2 \mathrm{~m}$.

The soil profiles we dug at the top of landslides \#1 to \#10 mostly exposed alternating layers of different texture and composition with different amounts of soil skeleton indicating former colluvial processes (Tables II and III; Figure 5).

On the shallowest landslides (\#4, \#5 and \#8), we found the shallowest soil profiles consisting of a single relatively thin soil layer above strongly weathered bedrock material. Soil substrates mostly originated from weathered limestone (phyllites). At higher elevations, we observed an increase of quarzites in the substrate composition. Soil textures ranged from lime-rich fine silt over clay to clay-rich fine sand. From undisturbed soil samples, we calculated dry soil densities $\left(\rho_{\mathrm{s}}\right)$ of $1342 \pm 220 \mathrm{~kg} \mathrm{~m}^{-3}$ (mean \pm standard error of mean, $n=33$ ).

Mainly owing to the high amount of clay and silt in the substrate composition, all of the investigated soils were cohesive. Field shear box experiments revealed soil cohesions $\left(C_{\mathrm{s}}\right)$ of 4.5 up to $20.8 \mathrm{kPa}(10.7 \pm 5.0 \mathrm{kPa}$, mean \pm standard error of mean, $n=17)$ and internal friction angles $(\phi)$ ranging from $25^{\circ}$ up to $51^{\circ}\left(36.9 \pm 9.6^{\circ}\right.$, mean \pm standard error of mean, $n=17$; Table IV). The strongest variation of soil cohesion $\left(C_{\mathrm{s}}\right)$ 
Table I. Results of landslide surveys. Geographic coordinates (UTM WGS84), elevation a.s.I. (Elv.), estimated landslide age, number of relative 3D coordinates $(n)$, planar length $\left(L_{\mathrm{p}}\right)$ and width $(W)$ of landslide, slopeangle $(\alpha)$ and visually estimated depth of failure $\left(h_{\mathrm{s}}\right)$

\begin{tabular}{|c|c|c|c|c|c|c|c|c|}
\hline \# & UTM WGS84 (m) & Elv. (m a.s.I.) & Age & $n$ & $L_{\mathrm{p}}(\mathrm{m})$ & $W(\mathrm{~m})$ & $\alpha\left(^{\circ}\right)$ & $h_{\mathrm{s}}(\mathrm{m})$ \\
\hline 1 & $714,096 / 9,558,503$ & 2528 & Fresh & 111 & 30.75 & 7.79 & 53.11 & 0.42 \\
\hline 2 & $714,460 / 9,558,210$ & 2656 & Fresh & 96 & 35.36 & 6.97 & 49.10 & 0.39 \\
\hline 3 & $713,883 / 9,558,019$ & 2510 & Fresh & 119 & 62.42 & 11.95 & 35.68 & 0.49 \\
\hline 4 & $713,736 / 9,558,058$ & 2500 & Fresh & 134 & 51.57 & 15.71 & 38.32 & 0.08 \\
\hline 5 & $713,961 / 9,559,726$ & 2219 & Fresh & 65 & 6.97 & 8.78 & 54.76 & 0.06 \\
\hline 6 & $713,973 / 9,559,758$ & 2203 & Old & 105 & 31.27 & 10.63 & 37.14 & 0.60 \\
\hline 7 & $713,967 / 9,559,419$ & 2294 & Old & 125 & 43.12 & 10.10 & 37.00 & 0.40 \\
\hline 8 & $713,884 / 9,559,444$ & 2136 & Old & 132 & 41.22 & 11.51 & 37.75 & 0.20 \\
\hline 9 & $713,084 / 9,560,181$ & 1893 & Old & 102 & 34.92 & 22.62 & 32.99 & 1.33 \\
\hline 10 & $713,213 / 9,560,460$ & 1820 & Fresh & 54 & 12.38 & 8.28 & 31.25 & 0.62 \\
\hline 11 & $713,455 / 9,560,350$ & 1983 & Old & 99 & 55.14 & 15.66 & 38.60 & 1.02 \\
\hline
\end{tabular}

Table II. Soil profiles (part 1). Number of associated landslide, vertical soil depth ( $\mathrm{z}$ ), horizon, texture and consistency shortcuts after Jahn et al. (2006), size (F: 2..6 mm; M: 6..20 mm; C: 20..60 mm; S: 60..200 mm) and abundance (N, none; V: 0...2\%; F: 2..5\%; C: 5...15\%; M: $15 . .40 \%$; A: 40.. 80\%; D: $<80 \%$; S, stone line) of soil skeleton, soil cohesion as measured by torsion probe $\left(C_{\mathrm{s}} ; \mathrm{Geonor} \mathrm{H}-60 ;\right.$ mean \pm standard error of mean), dry soil density ( $\rho_{\mathrm{s}} ;$ mean \pm standard error of mean; $n=3$ ) and gravimetric soil water content $(\Theta ;$ mean $\pm \operatorname{standard}$ error of mean; $n=3$ )

\begin{tabular}{|c|c|c|c|c|c|c|c|c|}
\hline \multirow[b]{2}{*}{$\#$} & \multirow[b]{2}{*}{$z(\mathrm{~cm})$} & \multirow[b]{2}{*}{ Symbol } & \multirow[b]{2}{*}{ Texture } & \multirow[b]{2}{*}{ Consist. } & Skeleton & \multirow[b]{2}{*}{$C_{\mathrm{s}}(\mathrm{kPa})$} & \multirow[b]{2}{*}{$\rho_{\mathrm{s}}\left(\mathrm{t} \mathrm{m}^{-3}\right)$} & \multirow[b]{2}{*}{$\Theta(\%)$} \\
\hline & & & & & Size/abundance & & & \\
\hline 1 & 25 & $\mathrm{O}$ & & & & - & - & - \\
\hline 1 & 20 & Oe & & & & - & - & - \\
\hline 1 & -20 & Ah & Sil & ko4 & $\mathrm{FM} / \mathrm{F}$ & $25.3 \pm 3.1 ; n=3$ & $1.04 \pm 0.15$ & $34.4 \pm 4.0$ \\
\hline 1 & -50 & A & $\mathrm{CL}$ & ko4 & $\mathrm{FM} / \mathrm{F}$ & $37.7 \pm 7.5 ; n=3$ & $1.18 \pm 0.02$ & $26.8 \pm 3.1$ \\
\hline 1 & -63 & Bw & Sil & ko4 & $\mathrm{FM} / \mathrm{F}$ & $23.0 \pm 3.6 ; n=3$ & $1.39 \pm 0.04$ & $19.0 \pm 0.8$ \\
\hline 1 & -80 & B & LS & so & $\mathrm{FM} / \mathrm{V}$ & $23.7 \pm 10.8 ; n=3$ & $1.45 \pm 0.10$ & $18.6 \pm 2.5$ \\
\hline 1 & -115 & $\mathrm{Cb}$ & LS & so & $\mathrm{FM} / \mathrm{S}$ & - & $1.50 \pm 0.09$ & $17.8 \pm 0.9$ \\
\hline 1 & -135 & $\mathrm{Cw}$ & LS & lo & $\mathrm{FM} / \mathrm{M}$ & $23.3 \pm 8.1 ; n=3$ & - & - \\
\hline 1 & -200 & $\mathrm{C}$ & & ko2 & $\mathrm{S}$ & $47.7 \pm 7.1 ; n=3$ & - & - \\
\hline 2 & 15 & $\mathrm{O}$ & & & & - & - & - \\
\hline 2 & 8 & Oe & & & & - & - & - \\
\hline 2 & -20 & $\mathrm{Ah}$ & SL & ko4 & $\mathrm{N}$ & $18.7 \pm 4.0 ; n=3$ & $1.41 \pm 0.03$ & $24.3 \pm 0.5$ \\
\hline 2 & -90 & B & $\mathrm{SL}$ & ko1 & $\mathrm{N}$ & $29.7 \pm 5.1 ; n=3$ & $1.60 \pm 0.03$ & $17.8 \pm 1.0$ \\
\hline 2 & -100 & $\mathrm{Cb}$ & & & $\mathrm{S}$ & $43.3 \pm 6.1 ; n=3$ & - & - \\
\hline 2 & -145 & Bwb & LS & ko1 & $\mathrm{FM} / \mathrm{C}$ & $45.7 \pm 9.5 ; n=3$ & $1.51 \pm 0.08$ & $16.2 \pm 1.9$ \\
\hline 2 & -160 & Bw & LS & ko1 & $\mathrm{M} / \mathrm{V}$ & $41.7 \pm 3.2 ; n=3$ & $1.50 \pm 0.06$ & $17.6 \pm 0.2$ \\
\hline 2 & -225 & $\mathrm{Cw}$ & & & $\mathrm{S}$ & $40.7 \pm 22.1 ; n=3$ & - & - \\
\hline 3 & 15 & $\mathrm{O}$ & & & & - & - & - \\
\hline 3 & 10 & $\mathrm{Oe}$ & & & & - & - & - \\
\hline 3 & -5 & $\mathrm{Ah}$ & & & & $16.0 \pm 2.8 ; n=2$ & - & - \\
\hline 3 & -30 & $\mathrm{Ah}$ & FS & & MC/D & $41.3 \pm 5.0 ; n=3$ & - & - \\
\hline 3 & -57 & Bw & FS & ko1 & $\mathrm{FM} / \mathrm{F}$ & $46.0 \pm 1.7 ; n=3$ & $1.68 \pm 0.04$ & $16.3 \pm 0.3$ \\
\hline 3 & -102 & $\mathrm{Cw}$ & VFS & ko1 & $\mathrm{CS} / \mathrm{A}$ & $63.3 \pm 6.1 ; n=3$ & $1.56 \pm 0.07$ & $17.9 \pm 1.3$ \\
\hline 3 & -130 & $\mathrm{C}$ & FS & ko1 & $\mathrm{N}$ & $46.0 \pm 2.0 ; n=3$ & $1.72 \pm 0.04$ & $16.8 \pm 0.1$ \\
\hline 4 & -10 & $\mathrm{Ah}$ & $\mathrm{L}$ & ko4 & $\mathrm{N}$ & $44.3 \pm 13.1 ; n=3$ & $1.44 \pm 0.15$ & $20.6 \pm 5.1$ \\
\hline 4 & -140 & $\mathrm{Cw}$ & FS & ko3 & $\mathrm{N}$ & $63.7 \pm 22.2 ; n=3$ & $1.49 \pm 0.02$ & $20.0 \pm 0.3$ \\
\hline 5 & 10 & $\mathrm{O}$ & & & & - & - & - \\
\hline 5 & -20 & $\mathrm{Ah}$ & SiL & ko4 & $\mathrm{N}$ & $14.5 \pm 2.8 ; n=3$ & - & - \\
\hline
\end{tabular}

was observed at landslide \#9, ranging from $4.5 \pm 2.1 \mathrm{kPa}$ at at a depth of $1.3 \mathrm{~m}$ up to $20.8 \pm 5.0 \mathrm{kPa}$ at $0.6 \mathrm{~m}$ (Figure 5).

As expected, measurements with a small torsion probe mostly yielded higher values of soil cohesion ranging from 8.1 to $70 \mathrm{kPa}(30.9 \pm 16.1 \mathrm{kPa}$, mean \pm standard error of mean, $n=119$, Tables II and III). Both methods are sensitive to coarse stone fragments in the shear plane that can cause overestimation of soil cohesion. We think that this effect is smaller in the field shear box due to the comparably bigger shear plane. Thus we recommend using a torsion probe only for soils without or at least with only small stones $(d<5 \mathrm{~mm})$ in the soil skeleton.
Using a field shear box we were able to estimate the quality of each measurement by inspecting the amount of stones in the shear plane after the experiment.

We conducted 39 point investigations of vegetation-related parameters (Table $\mathrm{V}$ ) and calculated above-ground tree biomass estimates of $130 \pm 54 \mathrm{t} \mathrm{ha}^{-1}$ (mean \pm standard error of mean, $n=3)$ in the lower altitudinal range $(<2050 \mathrm{~m}$ a.s.l. $)$, of $117 \pm 108 \mathrm{t} \mathrm{ha}^{-1}$ (mean \pm standard error of mean, $n=21$ ) in the intermediate altitudinal range (2050-2350 $\mathrm{m}$ a.s.l.) and of $53 \pm 30 \mathrm{t} \mathrm{ha}^{-1}$ (mean \pm standard error of mean, $n=14$ ) in the upper altitudinal range ( $>2350 \mathrm{~m}$ a.s.l.). 
Table III. Soil profiles (part 2). Number of associated landslide, vertical soil depth (z), horizon, texture and consistency shortcuts after Jahn et al. (2006), size (F: 2..6 mm; M: 6..20 mm; C: 20..60 mm; S: 60..200 mm) andabundance (N, none; V: 0..2\%; F:2..5\%; C:5..15\%; $\mathrm{M}: 15 \ldots 40 \%$; A:40 . .80\%; D: $<80 \%$; S, stone line) of soil skeleton, Soil cohesion as measured by torsion probe $\left(C_{\mathrm{s}} ;\right.$ Geonor $\mathrm{H}-60 ;$ mean \pm standard error of mean), dry soil density ( $\rho_{\mathrm{s}} ;$ mean \pm standard error of mean; $n=3$ ) and gravimetric soil water content $(\Theta ;$ mean \pm standard error of mean; $n=3$ )

\begin{tabular}{|c|c|c|c|c|c|c|c|c|}
\hline \multirow[b]{2}{*}{$\#$} & \multirow[b]{2}{*}{$z(\mathrm{~cm})$} & \multirow[b]{2}{*}{ Symbol } & \multirow[b]{2}{*}{ Texture } & \multirow[b]{2}{*}{ Consist. } & \multicolumn{2}{|l|}{ Skeleton } & \multirow[b]{2}{*}{$\rho_{\mathrm{s}}\left(\mathrm{t} \mathrm{m}^{-3}\right)$} & \multirow[b]{2}{*}{$\Theta(\%)$} \\
\hline & & & & & Size/abundance & $C_{\mathrm{s}}(\mathrm{kPa})$ & & \\
\hline 6 & 15 & $\mathrm{O}$ & & & & - & - & - \\
\hline 6 & -20 & $\mathrm{Ah}$ & $\mathrm{L}$ & ko4 & $\mathrm{FM} / \mathrm{C}$ & $22.7 \pm 1.6 ; n=3$ & $0.80 \pm 0.17$ & $45.3 \pm 7.9$ \\
\hline 6 & -75 & $\mathrm{Cw}$ & $\mathrm{SCL}$ & ko5 & $\mathrm{MC} / \mathrm{A}$ & $41.3 \pm 25.3 ; n=3$ & $1.30 \pm 0.00$ & $24.1 \pm 0.1$ \\
\hline 6 & -110 & $\mathrm{C}$ & & - & $\mathrm{S}$ & $70.0 \pm 17.8 ; n=3$ & 1.50 & 16.8 \\
\hline 7 & 5 & Oe & & & & - & - & - \\
\hline 7 & -9 & $\mathrm{Ah}$ & $\mathrm{L}$ & ko4 & $\mathrm{N}$ & $13.3 \pm 1.5 ; n=3$ & $1.04 \pm 0.17$ & $36.0 \pm 4.6$ \\
\hline 7 & -40 & $\mathrm{Bw}$ & SiL & ko4 & $\mathrm{M} / \mathrm{F}$ & $10.8 \pm 3.8 ; n=3$ & $1.00 \pm 0.34$ & $37.7 \pm 12.7$ \\
\hline 7 & -56 & $\mathrm{Cw}$ & $\mathrm{L}$ & ko3 & $\mathrm{CS} / \mathrm{A}$ & $27.8 \pm 2.0 ; n=3$ & $1.31 \pm 0.31$ & $27.7 \pm 10.1$ \\
\hline 7 & -95 & $\mathrm{C}$ & & & $\mathrm{S}$ & $48.7 \pm 17.8 ; n=3$ & - & - \\
\hline 8 & 150 & $\mathrm{O}$ & & & & - & - & - \\
\hline 8 & -22 & $\mathrm{Ah}$ & $\mathrm{L}$ & ko4 & $\mathrm{FM} / \mathrm{F}$ & $32.7 \pm 3.2 ; n=3$ & $1.20 \pm 0.13$ & $26.5 \pm 4.7$ \\
\hline 9 & 30 & $\mathrm{O}$ & & & & - & - & - \\
\hline 9 & -20 & $\mathrm{Ah}$ & SC & ko4 & $\mathrm{C} / \mathrm{A}$ & $15.8 \pm 3.4 ; n=3$ & $1.04 \pm 0.18$ & $29.9 \pm 8.9$ \\
\hline 9 & -45 & $\mathrm{Bw}$ & LS & ko1 & $\mathrm{MC} / \mathrm{C}$ & $14.5 \pm 8.2 ; n=3$ & $1.47 \pm 0.08$ & $13.1 \pm 2.3$ \\
\hline 9 & -55 & Bs & LS & ko1 & $\mathrm{MC} / \mathrm{C}$ & $9.7 \pm 4.7 ; n=3$ & $1.35 \pm 0.12$ & $14.4 \pm 1.6$ \\
\hline 9 & -150 & $\mathrm{Cb}$ & LS & ko1 & $\mathrm{MC} / \mathrm{C}$ & $20.0 \pm 7.8 ; n=3$ & $1.43 \pm 0.08$ & $10.8 \pm 1.3$ \\
\hline 9 & -158 & $\mathrm{Ab}$ & LS & ko1 & $\mathrm{F} / \mathrm{M}$ & $43.3 \pm 13.3 ; n=3$ & $1.35 \pm 0.06$ & $12.1 \pm 1.0$ \\
\hline 9 & -190 & Bwb & $\mathrm{Si}$ & ko1 & $S$ & $19.0 \pm 3.0 ; n=3$ & $1.38 \pm 0.02$ & $38.1 \pm 1.6$ \\
\hline 9 & -230 & Bsh & $\mathrm{Si}$ & ko1 & $\mathrm{F} / \mathrm{F}$ & $15.3 \pm 2.8 ; n=3$ & $1.15 \pm 0.25$ & $43.4 \pm 6.0$ \\
\hline 9 & -235 & $\mathrm{Cw}$ & $\mathrm{Si}$ & ko1 & $\mathrm{F} / \mathrm{F}$ & $11.8 \pm 1.3 ; n=3$ & 1.31 & 39.0 \\
\hline 9 & -290 & $\mathrm{C}$ & $\mathrm{Si}$ & ko1 & $/ M$ & $17.3 \pm 2.6 ; n=3$ & $1.44 \pm 0.03$ & $35.5 \pm 5.7$ \\
\hline 10 & 5 & $\mathrm{O}$ & & & & - & - & - \\
\hline 10 & -72 & $\mathrm{Ah}$ & $\mathrm{L}$ & ko3 & $\mathrm{C} / \mathrm{M}$ & $8.1 \pm 2.1 ; n=3$ & $0.90 \pm 0.13$ & $36.5 \pm 1.7$ \\
\hline 10 & -105 & $\mathrm{Cw}$ & $\mathrm{SCL}$ & ko4 & $\mathrm{C} / \mathrm{M}$ & $23.7 \pm 1.6 ; n=3$ & $1.32 \pm 0.06$ & $19.1 \pm 2.1$ \\
\hline
\end{tabular}

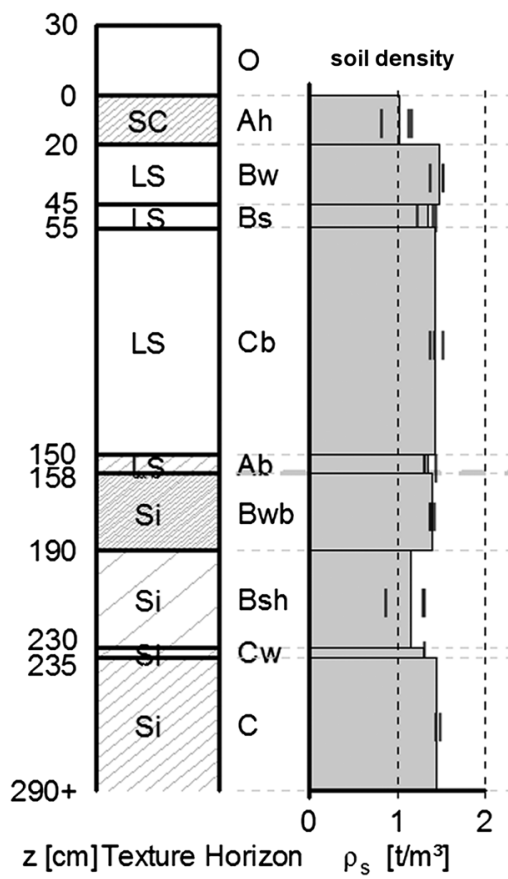

- Estimated depth of failure

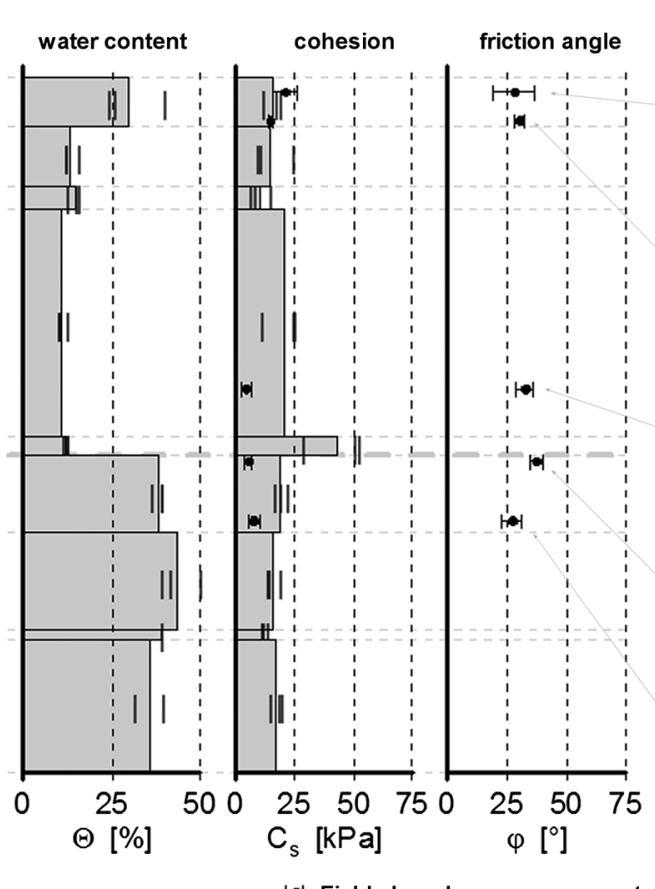

Field shear box measurements

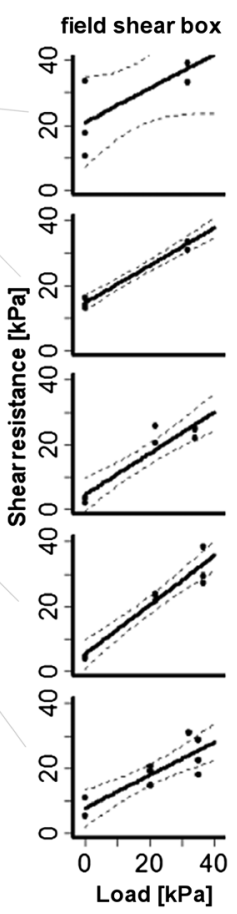

Figure 5. Overview of soil physical assessment of landslide \#9. From left to right: soil profile (soil texture abbreviations: SC, sandy clay; LS, loamy sand; $\mathrm{Si}$, silt; the abundance of soil skeleton is indicated by the darkness of shading); soil horizon; dry soil density ( $\rho_{\mathrm{s}}$ ) and gravimetric in situ soil water content $(\Theta)$ obtained from three undisturbed samples per horizon (single values indicated by small vertical lines); soil cohesion $\left(C_{\mathrm{s}}\right)$ measured by torsion probe (shaded in grey) and obtained from field shear box measurements at five depths (black dots; standard errors are indicated by whiskers), internal friction angles $(\phi)$, linear regression diagrams obtained by field shear boxexperiments. 
Table IV. In situ soil shear tests conducted with field shear box. Associated landslide number, vertical depth within the soil profile $(z)$, total number of shear tests $(n)$, number of different loads ( $\left.n_{\text {loads }}\right)$, soil cohesion $\left(C_{\mathrm{s}}\right.$; mean \pm standard error of mean) and internal friction angle ( $\phi$; mean \pm standard error of mean) calculated by linear regression (Equation (3)

\begin{tabular}{lrrrrrr}
\hline$\#$ & Landslide & $z(\mathrm{~m})$ & $n$ & $n_{\text {loads }}$ & \multicolumn{1}{c}{$C_{\mathrm{s}}(\mathrm{kPa})$} & $\phi\left(^{\circ}\right)$ \\
\hline 1 & 1 & 0.40 & 8 & 4 & $11.16 \pm 2.70$ & $37.5 \pm 6.9$ \\
2 & 1 & 0.70 & 8 & 4 & $7.08 \pm 0.93$ & $46.3 \pm 2.1$ \\
3 & 1 & 0.90 & 8 & 4 & $5.22 \pm 2.11$ & $43.0 \pm 4.7$ \\
4 & 1 & 0.95 & 7 & 2 & $12.44 \pm 1.39$ & $40.0 \pm 1.6$ \\
5 & 1 & 1.25 & 14 & 2 & $4.65 \pm 0.97$ & $25.8 \pm 1.9$ \\
6 & 2 & 0.30 & 6 & 3 & $10.21 \pm 2.19$ & $50.9 \pm 4.3$ \\
7 & 5 & 0.20 & 30 & 5 & $4.96 \pm 6.32$ & $46.9 \pm 7.7$ \\
8 & 6 & 0.30 & 6 & 3 & $14.31 \pm 1.13$ & $41.4 \pm 5.1$ \\
9 & 7 & 0.23 & 6 & 3 & $15.06 \pm 1.97$ & $32.8 \pm 8.6$ \\
10 & 7 & 0.40 & 6 & 3 & $12.86 \pm 1.50$ & $46.4 \pm 4.8$ \\
11 & 9 & 0.06 & 6 & 2 & $20.79 \pm 4.99$ & $27.7 \pm 9.2$ \\
12 & 9 & 0.18 & 6 & 2 & $14.61 \pm 0.86$ & $30.1 \pm 1.6$ \\
13 & 9 & 1.30 & 8 & 3 & $4.53 \pm 2.10$ & $32.6 \pm 3.5$ \\
14 & 9 & 1.60 & 9 & 3 & $5.31 \pm 1.88$ & $37.2 \pm 2.7$ \\
15 & 9 & 1.85 & 10 & 4 & $7.69 \pm 2.43$ & $27.0 \pm 4.4$ \\
16 & $11 a$ & 1.20 & 15 & 3 & $16.17 \pm 1.91$ & $40.2 \pm 3.1$ \\
17 & 11 & 1.20 & 12 & 3 & $15.23 \pm 3.26$ & $24.7 \pm 7.1$ \\
\hline \multirow{2}{*}{ a } & & & & & &
\end{tabular}

${ }^{\mathrm{a}}$ Measurement on the sliding surface.

${ }^{\mathrm{b}}$ Saturated conditions.

As expected, we found strong variations in tree densities and vegetation composition even between point investigations conducted within one altitudinal range (see Figure 6a). A decrease of above-ground tree biomass density with altitude a.s.l. has, for example, been reported by Leuschner et al. (2007), who estimated above-ground tree biomass between 132 and $199 \mathrm{t} \mathrm{ha}^{-1}$ at an altitude of $1890 \mathrm{~m}$ a.s.l. and between 74 and $127 \mathrm{t} \mathrm{ha}^{-1}$ at 2380 $\mathrm{m}$ a.s.l. using the same allometric equation that we used. Moser et al. (2008) used a different allometric equation for estimating above-ground tree biomass and found $173 \mathrm{t} \mathrm{ha}^{-1}$ at $1890 \mathrm{~m}$ a.s.l. and $100 \mathrm{t} \mathrm{ha}^{-1}$ at $2380 \mathrm{~m}$ a.s.l. Although the decrease of above-ground tree biomass density with altitude is not straightforward (Figure 6a), a linear regression through our measurements is significant at $\alpha=0.10$ ( $t$-test, $P$-value $=0.06)$, and we used the regression model to estimate an above-ground biomass range for each landslide.

Organic layer thickness $\left(h_{0}\right)$ varied strongly between the single sites (Figure 6b) and amounted to $0.35 \pm 0.21 \mathrm{~m}$ (mean \pm standard error of mean; $n=306$ ). The slight increase of organic layer thickness with altitude was not significant ( $P$-value: 0.41$)$. Thus we used the global mean value assuming a log-normal distribution.

In situ organic layer density, as calculated from 64 samples and a total sample volume of $2.81 \mathrm{~m}^{3}$, resulted in $208.1 \pm 89.0 \mathrm{~kg} \mathrm{~m}^{-3}$ (mean \pm standard error of mean). Density of the saturated organic layer, as derived from 15 samples and a total sample volume of $0.59 \mathrm{~m}^{3}$, resulted in $278 \pm 86.7 \mathrm{~kg} \mathrm{~m}^{-3}$ (mean \pm standard error of mean). Using these values, we calculated the average mass of the organic layer to be $728 \pm 187 \mathrm{t} \mathrm{ha}^{-1}$ (up to $973 \pm 182 \mathrm{t} \mathrm{ha}^{-1}$ under wet conditions), which compares well with the values obtained by Wilcke et al. (2002), who estimated the mass of the organic layer in the study area to reach up to $713 \mathrm{tha}^{-1}$. For our analyses we used the estimate under wet conditions.

We conducted a total of 903 in situ organic layer rupture tests in nine organic layer profiles at three altitudinal levels of the study area (Table $\mathrm{VI}$ ) and found organic layer tensile resistance to vary from 1.84 to $2.69 \mathrm{kPa}(2.17 \pm 1.16 \mathrm{kPa}$, mean \pm standard error of mean, distribution: log-normal). We measured the force necessary to pull out a sample of the fine root matrix, not considering samples that contained roots with diameters significantly greater than $5 \mathrm{~mm}$. Larger roots, however, were encountered in less than $0.5 \%$ of all specimens. We think that by considering a log-normal distribution of organic layer resistance, we still account for the effect of bigger roots. Roots were untangled rather than torn apart during measurements and it is not surprising that measured values are low compared to laboratory rupture tests or other in situ direct shear tests that incorporate mineral soil (Schmidt et al., 2001). At landslide margins, we observed the ragged remains of the organic layer and did not encounter many torn roots. Thus we think that our experiments realistically covered the actual processes during a failure of the root mat, even though this mechanism may be unique to ecosystems with massive organic layers atop the mineral soil.

Tests conducted in the organic layer yielded $2.26 \pm 1.2 \mathrm{kPa}$ and tests conducted at the boundary to the mineral soil yielded $2.07 \pm 1.09 \mathrm{kPa}$, which is a significant reduction by $8.5 \%$ (Welch two sample $t$-test, $P=0.012$ ). However, a comparison of rupture tests conducted between the altitudinal ranges did not reveal any significant differences.

\section{Model application}

The number of torn roots on the failure surfaces of the investigated landslides was negligible. Thus we assumed that there is no root contribution to basal resistance $\left(x C_{0}=0\right)$. Taking into account the natural variability of $C_{\mathrm{s}}$ which we observed even within the same soil profile (see Figure 5) and assuming that a mechanical system always breaks at its weakest point, we used the observed minimum values and according uncertainties per soil profile in a first model application to five of the 11 landslides, where we measured the complete set of parameters (i.e. \#1, \#2, \#6, \#7 and \#9; Table VII). This application revealed a potential slope instability on landslides \#1 and \#9 (Figure 7a).

In the other three cases, the median factors of safety were greater than 2 and the $95 \%$ confidence bands do not cover
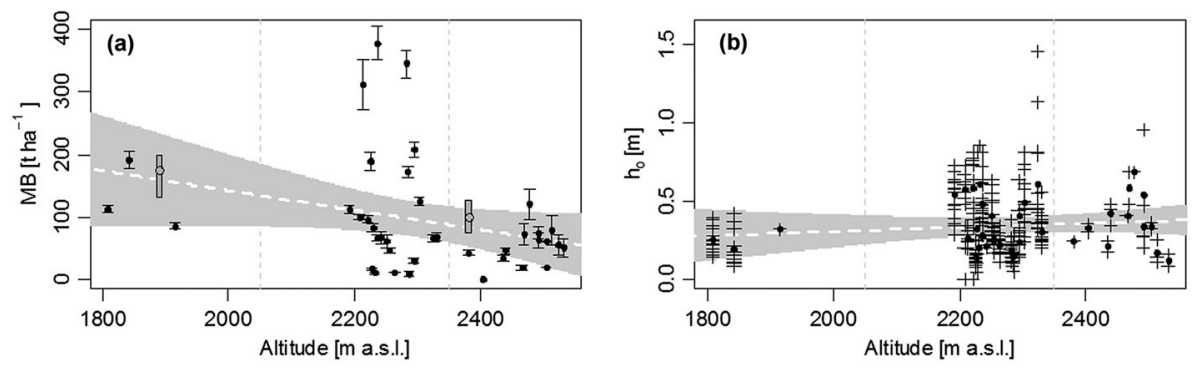

Figure 6. (a) Above-ground dry tree biomass densities (dots, mean values; whiskers, standard error of mean). The vertical bars at 1890 and $2380 \mathrm{~m}$ a.s.I. represent the estimations by Leuschner et al. (2007); points within the bars show estimations by Moser et al. (2008). (b) Organic layer thickness (dots, mean values; crosses, single measurements) at different altitudes. 95\% confidence limits of linear regressions are shaded in grey. 
Table V. Point investigations, ordered by elevation. Geographic coordinates (UTM WGS84), elevation a.s.I. (Elv.), slope angle ( $\alpha$ ), thickness of organic layer $\left(h_{\mathrm{o}}\right.$; mean \pm standard error of mean; number of samples), estimated mean tree height $(\bar{h})$, tree diameter in breastheight $(130$ cm; $\mathrm{DBH}$; mean \pm standard error of mean; number of samples) and above-ground dry tree biomass density estimates $\left(M_{B}\right.$, Equation (4); Brown, 1997)

\begin{tabular}{|c|c|c|c|c|c|c|c|}
\hline \# & UTM WGS84 (m) & Elv. (m a.s.I.) & $\alpha\left[^{\circ}\right]$ & $h_{\mathrm{o}}(\mathrm{m})$ & $\bar{h}(\mathrm{~m})$ & $\mathrm{DBH}(\mathrm{cm})$ & $M_{B}\left(\mathrm{~g} \mathrm{~m}^{-2}\right)$ \\
\hline 1 & $714,150 / 9,558,405$ & 2,531 & 38 & $0.12 \pm 0.05 .7 ; n=2$ & 4 & $12.57 \pm 7.16 ; n=4$ & 5090 \\
\hline 2 & $714,162 / 9,558,420$ & 2,524 & 30 & - & 5 & $8.48 \pm 7.04 ; n=8$ & 5568 \\
\hline 3 & $714,133 / 9,558,397$ & 2,514 & 28 & $0.17 \pm 0.07 ; n=3$ & 3.5 & $11.94 \pm 8.77 ; n=6$ & 7850 \\
\hline 4 & $714,089 / 9,558,513$ & 2,505 & 56 & $0.34 \pm 0.02 ; n=3$ & 3.5 & $5.37 \pm 1.82 ; n=35$ & 6047 \\
\hline 5 & $714,089 / 9,558,513$ & 2,505 & 36 & $0.34 \pm 0.02 ; n=3$ & 3 & $4.97 \pm 1.6 ; n=18$ & 1929 \\
\hline 6 & $714,090 / 9,558,399$ & 2,492 & 18 & $0.34 \pm 0.12 ; n=3$ & 4 & $12.14 \pm 6.05 ; n=8$ & 7454 \\
\hline 8 & $713,747 / 9,558,033$ & 2,478 & 40 & $0.69 ; n=1$ & 12 & $15 \pm 7.72 ; n=6$ & 12010 \\
\hline 9 & $713,724 / 9,558,063$ & 2,469 & 35 & $0.59 \pm 0.14 ; n=2$ & 7 & $12.22 \pm 8.79 ; n=5$ & 7196 \\
\hline 10 & $714,047 / 9,558,399$ & 2,466 & 40 & $0.41 \pm 0.00 ; n=2$ & 4 & $7.27 \pm 3.85 ; n=6$ & 1896 \\
\hline 11 & $714,065 / 9,558,476$ & 2,440 & 36 & $0.43 \pm 0.07 ; n=3$ & 6 & $6.53 \pm 3.36 ; n=19$ & 4569 \\
\hline 12 & $713,999 / 9,558,377$ & 2,436 & 49 & $0.21 \pm 0.05 ; n=2$ & 7 & $8.55 \pm 2.91 ; n=8$ & 3331 \\
\hline 13 & $713,970 / 9,558,355$ & 2,404 & 47 & $0.33 \pm 0.03 ; n=2$ & 3 & $4.77 ; n=1$ & 93 \\
\hline 14 & $713,922 / 9,558,338$ & 2,382 & 51 & $0.24 \pm 0.00 ; n=2$ & 5.5 & $7.51 \pm 3.16 ; n=12$ & 4272 \\
\hline 16 & $713,986 / 9,559,334$ & 2,325 & 45 & $0.61 \pm 0.35 ; n=13$ & 4 & $9.43 \pm 3.58 ; n=12$ & 6533 \\
\hline 17 & $713,992 / 9,559,348$ & 2,303 & 49 & $0.49 \pm 0.16 ; n=17$ & 4 & $8.97 \pm 3.7 ; n=23$ & 12557 \\
\hline 18 & $713,936 / 9,559,392$ & 2,295 & 28 & $0.24 \pm 0.07 ; n=11$ & 10 & $9.16 \pm 5.97 ; n=32$ & 20800 \\
\hline 19 & $713,976 / 9,559,428$ & 2,294 & 43 & $0.41 \pm 0.24 ; n=3$ & 4 & $8.79 \pm 2.47 ; n=8$ & 2971 \\
\hline 20 & $713,976 / 9,559,446$ & 2,287 & 36 & $0.15 \pm 0.12 ; n=3$ & 3 & $7.43 \pm 3.8 ; n=3$ & 830 \\
\hline 21 & $713,959 / 9,559,390$ & 2,285 & 36 & $0.15 \pm 0.05 ; n=10$ & 5 & $10.36 \pm 4.87 ; n=24$ & 17172 \\
\hline 22 & $714,014 / 9,559,348$ & 2,282 & 48 & $0.18 \pm 0.07 ; n=18$ & 8 & $13.18 \pm 6.31 ; n=21$ & 34473 \\
\hline 23 & $713,860 / 9,559,631$ & 2,264 & 36 & $0.22 \pm 0.06 ; n=17$ & 2.5 & $5.53 \pm 1.1 ; n=11$ & 1087 \\
\hline 24 & $713,857 / 9,559,681$ & 2,256 & 28 & $0.26 \pm 0.05 ; n=12$ & 5 & $7.6 \pm 3.33 ; n=17$ & 4661 \\
\hline 25 & $713,864 / 9,559,655$ & 2,252 & 36 & $0.41 \pm 0.12 ; n=17$ & 6 & $7.06 \pm 4.71 ; n=16$ & 6134 \\
\hline 26 & $713,953 / 9,559,686$ & 2,243 & 40 & $0.21 \pm 0.01 ; n=2$ & 6 & $10.47 \pm 4.78 ; n=9$ & 6728 \\
\hline 27 & $713,918 / 9,559,725$ & 2,236 & 10 & $0.28 \pm 0.00 ; n=2$ & 6.4 & $10.26 \pm 4.09 ; n=13$ & 6615 \\
\hline 28 & $713,896 / 9,559,704$ & 2,236 & 15 & $0.48 \pm 0.01 ; n=18$ & 6 & $9.15 \pm 7.93 ; n=44$ & 37758 \\
\hline 29 & $713,972 / 9,559,770$ & 2,232 & 36 & $0.61 \pm 0.04 ; n=2$ & 5 & $6.57 \pm 1.34 ; n=7$ & 958 \\
\hline 30 & $713,932 / 9,559,718$ & 2,229 & 40 & $0.20 \pm 0.06 ; n=2$ & 5 & $9.68 \pm 3.78 ; n=15$ & 8215 \\
\hline 31 & $713,982 / 9,559,756$ & 2,228 & 35 & $0.32 \pm 0.43 ; n=3$ & 5 & $7.87 \pm 1.91 ; n=7$ & 1600 \\
\hline 34 & $713,965 / 9,559,412$ & 2,214 & 52 & $0.26 \pm 0.05 ; n=9$ & 10 & $11.65 \pm 7.75 ; n=18$ & 31140 \\
\hline 35 & $713,819 / 9,559,775$ & 2,208 & 44 & $0.58 \pm 0.21 ; n=18$ & 7 & $7.67 \pm 3.49 ; n=28$ & 9926 \\
\hline 36 & $713,759 / 9,559,819$ & 2,192 & 36 & $0.54 \pm 0.14 ; n=18$ & 7 & $9.6 \pm 4.33 ; n=20$ & 11289 \\
\hline 37 & $713,234 / 9,560,163$ & 1,915 & 36 & $0.32 ; n=1$ & 5 & $6.87 \pm 2.92 ; n=37$ & 8,544 \\
\hline 38 & $713,248 / 9,560,451$ & 1,843 & 54 & $0.20 \pm 0.11 ; n=13$ & 7 & $10.79 \pm 4.97 ; n=18$ & 19132 \\
\hline 39 & $713,179 / 9,560,469$ & 1,809 & 45 & $0.26 \pm 0.08 ; n=14$ & 6 & $8.94 \pm 3.82 ; n=22$ & 11328 \\
\hline
\end{tabular}

Table VI. In situ organic layer rupture tests. Location i.d., minimum $\left(\tau_{\min }\right)$ and maximum $\left(\tau_{\max }\right)$ tensile resistance, mean value $(\tau)$

\begin{tabular}{|c|c|c|c|c|c|}
\hline \multirow{2}{*}{ Location } & \multirow{2}{*}{$\tau_{\min }(\mathrm{kPa})$} & \multirow{2}{*}{$\tau_{\max }(\mathrm{kPa})$} & \multirow{2}{*}{$\tau(\mathrm{kPa})$} & $\log (\tau)$ & \multirow[b]{2}{*}{$n$} \\
\hline & & & & $\log (\mathrm{kPa})$ & \\
\hline $\mathrm{a}$ & 0.89 & 3.25 & $2.41 \pm 0.88$ & $0.79 \pm 0.49$ & 11 \\
\hline$\varnothing$ & 0.89 & 3.25 & $2.41 \pm 0.88$ & $0.79 \pm 0.49$ & 11 \\
\hline$b$ & 0.32 & 5.47 & $1.89 \pm 1.01$ & $0.50 \pm 0.53$ & 205 \\
\hline b & 0.32 & 6.24 & $2.06 \pm 1.11$ & $0.58 \pm 0.54$ & 101 \\
\hline$b$ & 0.89 & 7.45 & $2.69 \pm 1.04$ & $0.92 \pm 0.39$ & 150 \\
\hline$b$ & 0.76 & 11.84 & $2.29 \pm 1.28$ & $0.72 \pm 0.44$ & 150 \\
\hline$\varnothing$ & 0.32 & 11.84 & $2.22 \pm 1.15$ & $0.67 \pm 0.50$ & 606 \\
\hline C & 0.76 & 5.60 & $2.63 \pm 1.15$ & $0.87 \pm 0.46$ & 39 \\
\hline C & 0.48 & 7.48 & $2.09 \pm 1.36$ & $0.55 \pm 0.64$ & 97 \\
\hline C & 0.64 & 3.82 & $2.04 \pm 0.71$ & $0.65 \pm 0.37$ & 51 \\
\hline C & 0.32 & 7.51 & $1.84 \pm 1.17$ & $0.45 \pm 0.57$ & 99 \\
\hline$\varnothing$ & 0.32 & 7.51 & $2.07 \pm 1.19$ & $0.58 \pm 0.57$ & 286 \\
\hline
\end{tabular}

the critical value of one. Measured values of soil shear resistance on these three landslides always were greater than the backcalculated shear resistance $\left(C_{\mathrm{s}}^{\text {crit. }}\right.$, Equation (16), Figure $\left.7 \mathrm{~b}\right)$ that would be necessary for failure.
On the one hand, this first application illustrates that the soil strength parameters we measured in situ on landslides \#2, \#6 and \#7 are higher than those leading to the actual slope failure in these cases. On the other hand, it shows that on landslides $\# 1$ and \#9 the critical situation may have arisen even without the scenario we assumed (complete saturation of soil column, $m=1$ ), while measurements of $C_{\mathrm{s}}$ and $\phi$ were accurate.

By aggregating the value ranges of required soil shear resistance ( $\left.C_{s}^{\text {crit. }}\right)$ of the five landslides we obtained a value range for soil cohesion of $C_{\mathrm{s}}=4.5 \pm 1.8 \mathrm{kPa}$. Applying these backcalculated value ranges to all landslides in a Monte Carlo simulation, $95 \%$ confidence ranges for the factor of safety cover the critical value of one in all but two cases (\#4 and \#8 in Figure 8a) which were among the shallowest landslides in our study. Here the $95 \%$ confidence band of required minimum soil depth (Figure 8b) also did not cover the observed values.

Median values of the factor of safety now indicate instability on five of the 11 landslides (i.e. \#1, \#2, \#6, \#9 and \#11), while median values of model predictions for the critical minimum soil depth all lie below $1 \mathrm{~m}$. Owing to the higher uncertainty of the conservative value range of $C_{\mathrm{s}}$, the confidence range of model predictions is wider compared to the direct application of our measurements (cf. Figure 7). We observe a higher 
Table VII. Model parameter values and associated uncertainties as obtained by field surveys. Elevation a.s.I. (Elv.), length ( $L$ ) and width ( $W$ ) of landslide, slope angle $(\alpha)$, above-ground dry tree biomass estimate $(\mathrm{MB})$, visually estimated depth of failure $\left(h_{\mathrm{s}}\right)$, soil cohesion $\left(C_{\mathrm{s}}\right)$, internal angle of friction $(\phi)$, dry soil density $\left(\rho_{\mathrm{s}}\right)$, organic layer density $\left(\rho_{\mathrm{o}}\right)$, organic layer cohesion $\left(C_{\mathrm{o}}\right)$ and organic layer thickness $\left(h_{\mathrm{o}}\right)$

\begin{tabular}{|c|c|c|c|c|c|c|c|c|}
\hline \# & Elv. (m) & $L(\mathrm{~m})$ & $W(\mathrm{~m})$ & $\alpha\left({ }^{\circ}\right)$ & $M B\left(\mathrm{~kg} \mathrm{~m}^{-2}\right)$ & $h_{\mathrm{s}}(\mathrm{m})$ & $C_{\mathrm{s}}(\mathrm{kPa})$ & $\phi\left(^{\circ}\right)$ \\
\hline 1 & 2528 & $30.8 \pm 0.1$ & $7.8 \pm 0.1$ & $53.1 \pm 0.3$ & $5.96 \pm 2.30$ & $0.42 \pm 0.05$ & $4.65 \pm 0.93$ & $25.8 \pm 4.7$ \\
\hline 2 & 2656 & $35.4 \pm 0.1$ & $7.0 \pm 0.1$ & $49.1 \pm 0.3$ & $3.95 \pm 3.19$ & $0.39 \pm 0.05$ & $10.21 \pm 2.19$ & $50.9 \pm 4.3$ \\
\hline 3 & 2510 & $62.4 \pm 0.1$ & $12.0 \pm 0.1$ & $35.7 \pm 0.2$ & $6.24 \pm 2.18$ & $0.49 \pm 0.05$ & - & - \\
\hline 4 & 2500 & $51.6 \pm 0.1$ & $15.7 \pm 0.1$ & $38.3 \pm 0.2$ & $6.40 \pm 2.12$ & $0.08 \pm 0.05$ & - & - \\
\hline 5 & 2219 & $7.0 \pm 0.1$ & $8.8 \pm 0.1$ & $54.8 \pm 1.1$ & $10.80 \pm 1.55$ & $0.06 \pm 0.05$ & $4.96 \pm 6.32$ & $46.9 \pm 7.7$ \\
\hline 6 & 2203 & $31.3 \pm 0.1$ & $10.6 \pm 0.1$ & $37.1 \pm 0.5$ & $11.05 \pm 1.61$ & $0.60 \pm 0.05$ & $14.31 \pm 1.13$ & $41.5 \pm 5.1$ \\
\hline 8 & 2136 & $41.2 \pm 0.1$ & $11.5 \pm 0.1$ & $37.7 \pm 0.2$ & $12.10 \pm 1.95$ & $0.20 \pm 0.05$ & - & - \\
\hline 9 & 1893 & $34.9 \pm 0.1$ & $22.6 \pm 0.1$ & $33.0 \pm 0.8$ & $15.90 \pm 3.62$ & $1.33 \pm 0.05$ & $5.31 \pm 1.88$ & $37.2 \pm 2.7$ \\
\hline 10 & 1820 & $12.4 \pm 0.1$ & $8.3 \pm 0.1$ & $31.2 \pm 2.3$ & $17.04 \pm 4.18$ & $0.62 \pm 0.05$ & - & - \\
\hline 11 & 1983 & $55.1 \pm 0.1$ & $15.7 \pm 0.1$ & $38.6 \pm 0.2$ & $14.50 \pm 2.96$ & $1.02 \pm 0.05$ & - & - \\
\hline
\end{tabular}

$\rho_{\mathrm{s}}=1400 \pm 100 \mathrm{~kg} \mathrm{~m}^{-3} ; \rho_{\mathrm{o}}=973 \pm 182 \mathrm{~kg} \mathrm{~m}^{-3} ; C_{\mathrm{o}}=2.26 \pm 1.2 \mathrm{kPa} ; h_{\mathrm{o}}=0.35 \pm 0.21 \mathrm{~m}$.
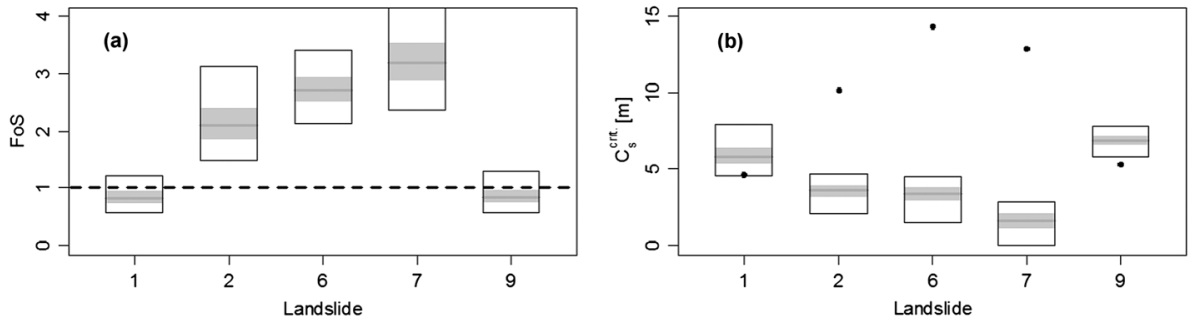

Figure 7. Direct model application to five landslides. (a) Factors of safety (FoS; horizontal dashed line marks the critical FoS of one). (b) Soil shear resistance as required for failure, given our measurements ( $C_{\mathrm{s}}^{\text {crit. }}$; black dots represent measured values of soil cohesion). Bars represent results of Monte Carlo simulations (outer frame, 95\% quantile; grey box, 50\% quantile; horizontal grey line, median).
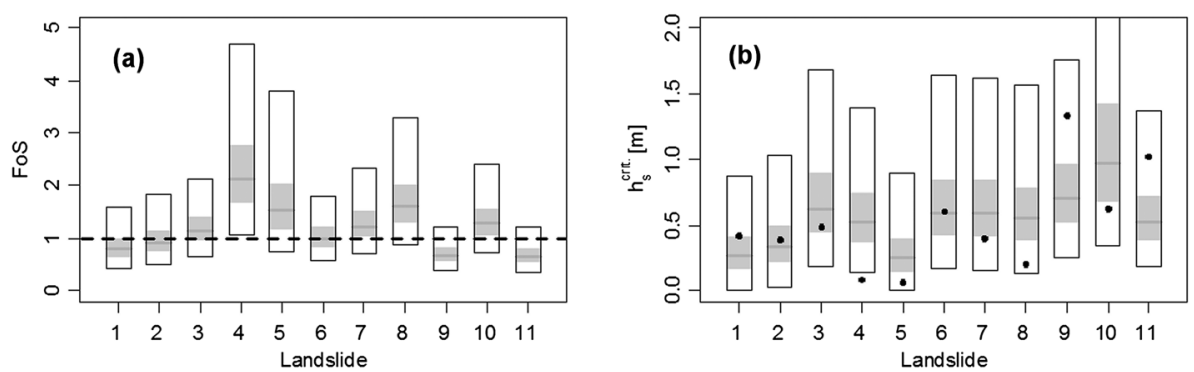

Figure 8. Model application to all 11 landslides using the back-calculated value range for soil cohesion $\left(C_{\mathrm{s}}\right)$. Factors of safety (FoS) (a) and critical minimum soil thickness $\left(h_{\mathrm{s}}^{\text {crit. }}(\mathrm{b})\right.$. Horizontal dashed line marks the critical FoS of one and black dots represent observed landslide depths $\left(h_{\mathrm{s}}\right)$. Bars represent results of Monte Carlo simulations (outer frame, 95\% quantile; grey box, 50\% quantile; horizontal grey line, median).

uncertainty in factor of safety predictions on the shallower landslides (\#4, \#5 and \#8 in Figure 8) compared to the others.

\section{Sensitivity analysis}

Exploring the influence of parameter uncertainties (Table VII) on the total variation of critical minimum soil depth $\left(\Delta h_{\mathrm{s}}^{\text {crit. }}\right.$, Figures 9 and 10), we found that soil cohesion $\left(C_{\mathrm{s}}\right)$ and internal friction angle $(\phi)$ were among the most influential parameters on all landslides, while the model always was most sensitive to the slope angle $(\alpha)$. Steeper slopes generally allow for shallower landslides, as indicated by the negative relative sensitivity $(S)$ to relative changes in $\alpha$. Due to the high accuracy in our measurements of $\alpha$ (cf. Table VII), however, the total contribution of this parameter to prediction uncertainty remained comparatively weak on most landslides, except for landslide 10 , where the measured accuracy was lowest.
As expected, soil cohesion $\left(C_{\mathrm{s}}\right)$ and internal friction angle $(\phi)$ acted as slope stabilizers on all landslides, while landslide length $(L)$ and width $(W)$ had a slightly destabilizing effect. The latter can be explained by the fact that an increase of the perimeter quadratically increases the basal area and the volume (and thus the destabilizing mass) of the sliding block. In addition, the ratio of perimeter and basal area $\left(\frac{2 L+W}{L W}\right)$ shrinks and reduces the contribution of lateral resistance. As expected, organic layer cohesion $\left(C_{\mathrm{o}}\right)$ acted as a contributor to slope stability on all landslides, while being relatively unimportant.

Parameters related to the weight load (i.e. $\rho_{\mathrm{s},} \rho_{\mathrm{O}}, h_{\mathrm{O}}$ and MB) all had relatively little effect on total model uncertainty on all landslides. Even though we allowed for extreme values of $M B$ regarding the strong natural variability we observed in this parameter, the contribution of above-ground biomass (40 up to $170 \mathrm{t} \mathrm{ha}^{-1}$ ) was always weaker than that of the mass of the organic layer (up to $973 \mathrm{t} \mathrm{ha}^{-1}$ under wet conditions). The relative sensitivity $(S)$ to changes in parameters related to the organic layer $\left(\rho_{\mathrm{o}}\right.$ and $h_{\mathrm{o}}$ ) was always about the same size as the relative 


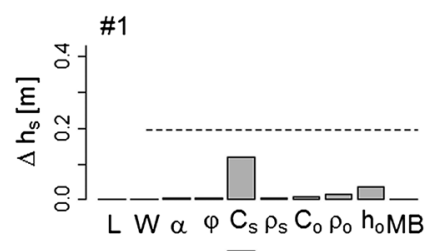

\#2

\#6
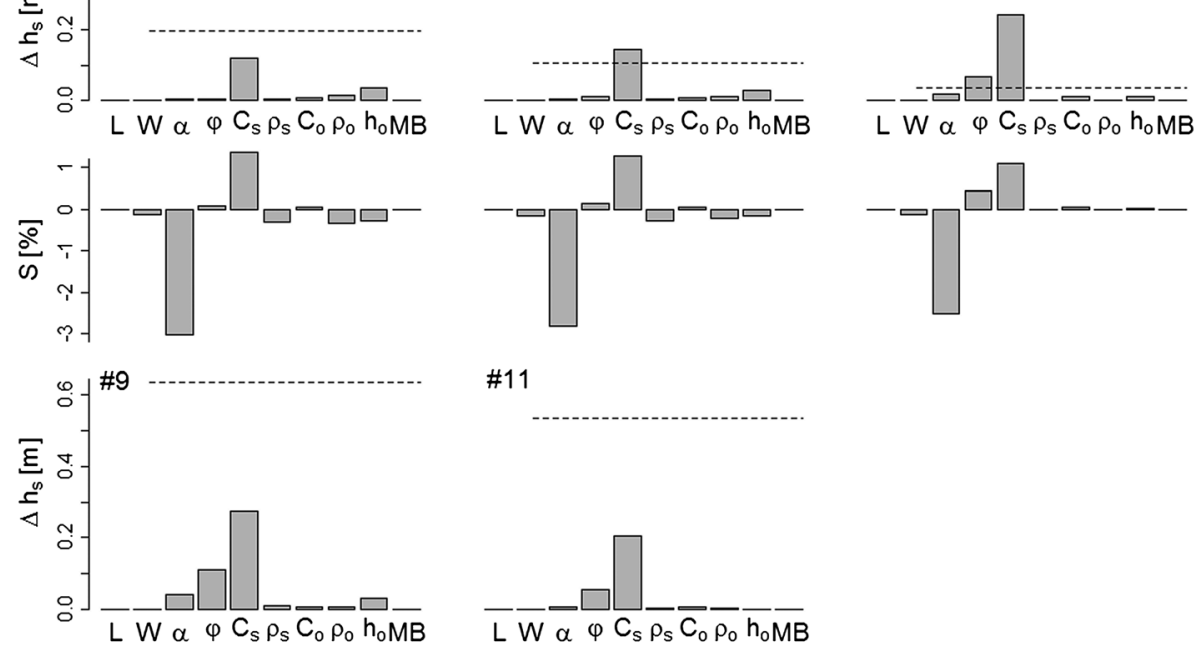

\#11
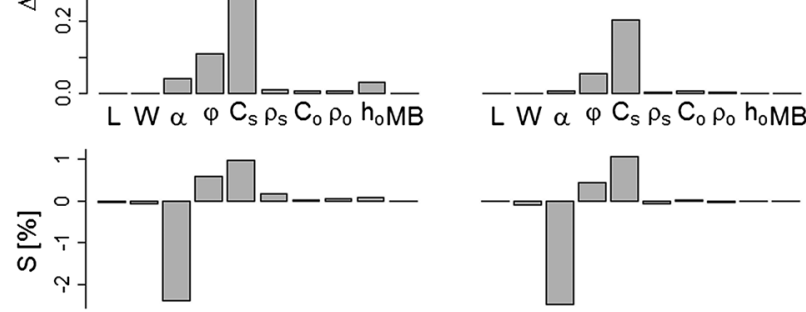

Figure 9. Model sensitivity analysis on landslides classified as unstable. Absolute contribution of parameter uncertainties to model uncertainty $\left(\Delta h_{\mathrm{s}}\right)$ and relative sensitivity $(S)$ of $h_{\mathrm{s}}^{\text {crit. }}$ to parameter variations. Horizontal dashed lines indicate the absolute difference between observed landslide depth and predicted mean value.

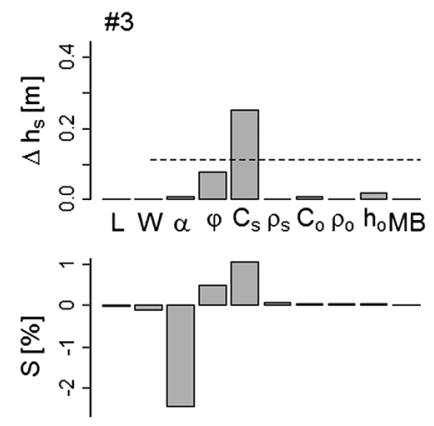

\#4
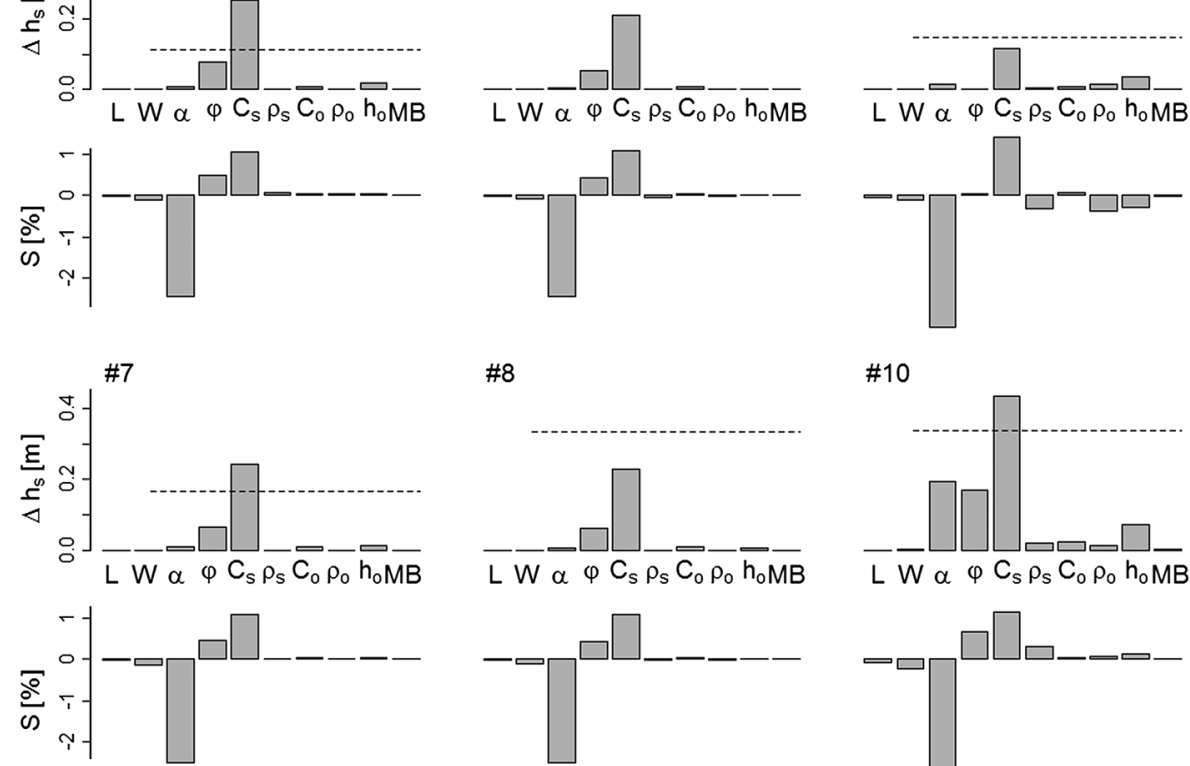

\#8

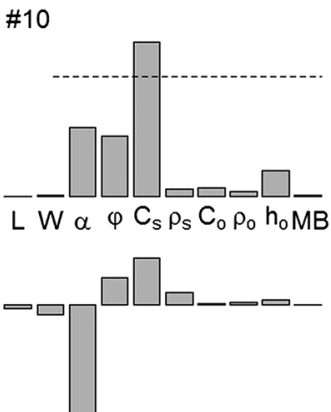

Figure 10. Relative model sensitivity analysis on landslides classified as stable. Absolute contribution ( $\Delta h_{\mathrm{s}}^{\text {crit. }}$ ) of parameter uncertainties to model uncertainty and relative sensitivity $(S)$ of $h_{\mathrm{s}}^{\text {crit. }}$ to parameter variations. Horizontal dashed lines indicate the absolute difference between observed landslide depth and predicted value.

sensitivity to parameters related to the mineral soil $\left(\rho_{\mathrm{s}}\right)$, indicating that both factors are of similar importance.

The model correctly predicted instability on five of the 11

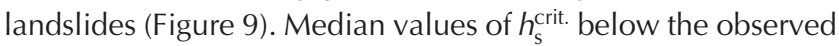
landslide depth (cf. Figure 8) indicate that, on these landslides, failure may have occurred even without the worst-case scenario we assumed $(m=1)$. Six of the landslides (Figure 10) were basically classified as stable while, again, parameter uncertainties (cf. Figure 8) allow an explanation this overestimation of slope stability in most cases. On two landslides (i.e. \#4 and \#8, Figure 10), the model predicted stability, while the 95\% confidence ranges of prediction uncertainty (Figure 8) did not cover the observed landslide depth, indicating that variation of all parameters in the range of their uncertainty does not reproduce the shallowness of these landslides. Thus, in these two cases, even the worst-case scenario in which we assumed complete saturation of the mineral soil $(m=1)$ was insufficient to explain the slope failure. We have to consider that either the water 

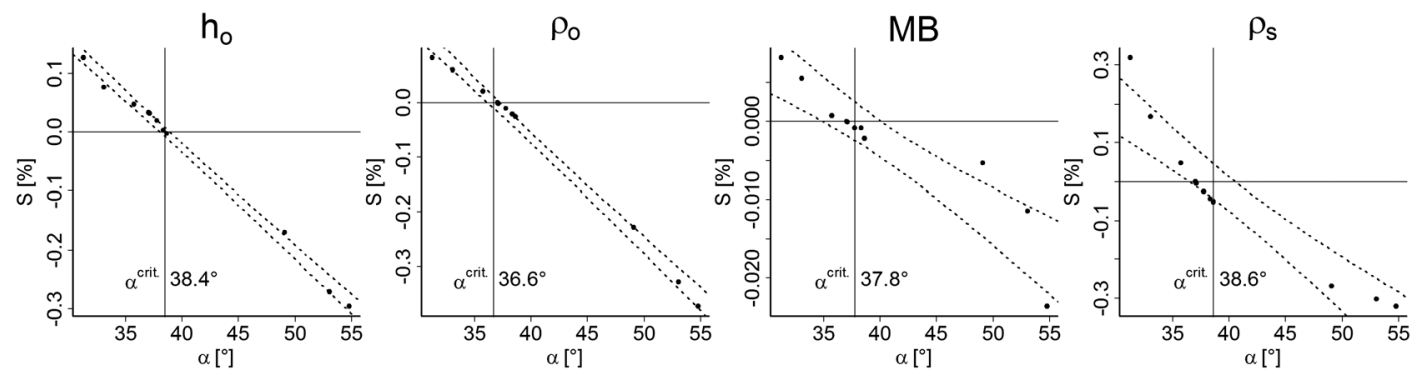

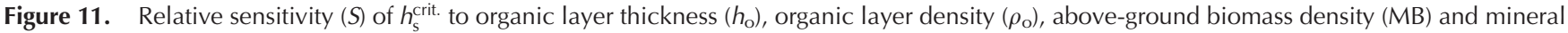
soil density $\left(\rho_{\mathrm{s}}\right)$ in relation to landslide slope angle $(\alpha)$.

table reached into the organic layer $(m>1)$ or other factors that have not been covered by the field survey, such as trees transferring wind forces into the ground (cf. Sidle and Ochiai, 2006), played an important role for the initiation of these landslides.

As expected, parameters that contribute to the weight load $(G)$ of the sliding block (i.e. $\rho_{\mathrm{s}}, \rho_{\mathrm{o}}, h_{\mathrm{o}}$ and MB) acted as stabilizers on landslides with low slope angles and caused a destabilizing effect on the steeper slopes. This relationship is more evident when plotting the relative sensitivity $(S)$ to these parameters as a function of landslide slope angle (Figure 11). By means of linear regression we found a slope angle $\left(\alpha^{\text {crit. }}=37.9^{\circ} \pm 0.9^{\circ}\right)$ determining the point at which these parameters started to contribute to slope instability. Considering the distribution of average slope angles in the study area $\left(\alpha=33^{\circ} \pm 12^{\circ}\right.$; Vorpahl et al., 2012), we estimate that $31 \%$ up to $36 \%$ of the entire study area is prone to this destabilizing effect. On all landslides, slope stability is equally sensitive to the mass of organic layer and mineral soil, while we expect vegetation-related parameters to vary faster with time than others. Thus, on steep slopes $\left(\alpha>\alpha^{\text {crit. }}\right)$, we expect a dynamically increasing destabilizing effect of the growing organic layer.

Comparing the average organic layer mass to above-ground biomass and to the mass of mineral soil on the single landslides, we found that the contribution of vegetation to the sliding mass is comparatively small on deep landslides, while on shallower landslides more than half of the sliding mass consisted of organic matter. These results are based on observations from a sample of 11 landslides. Thus we cannot provide an estimate on the percentage of shallow landslides. Nonetheless, we think our observations are representative and vegetation provides an important preparatory factor for landslide initiation in the study area mainly by contributing to the growing mass of the organic layer on steep slopes.

\section{Conclusion}

We investigated 11 shallow translational landslides in a tropical montane rainforest in the Andes of southern Ecuador and measured all important environmental factors for slope stability. To investigate a possible contribution of vegetation to slope instability on these landslides, we used a standard model for shallow slope stability after Gabet and Dunne (2002) and Casadei et al. (2003), which we modified by representing the soil as two units: a mineral and an organic layer. In this way we regarded the special situation of plant roots growing in a massive organic layer above the mineral soil rather than penetrating it.

Assuming a worst-case scenario in which there is complete saturation of the mineral soil column and assuming hydrostatic hydraulic conditions rather than slope-parallel flow, we directly applied the model to our measurements and found that, even though measurements of soil strength parameters were accurate, they do not accurately reflect the soil strength at the time of failure in all cases. Using a back-calculated distribution of soil cohesion values $\left(C_{\mathrm{s}}=4.5 \pm 1.8 \mathrm{kPa}\right)$ that would have been necessary for failure, the model was able to explain failure on nine of the 11 landslides. In the remaining two cases, we have to consider that either the scenario we assumed (complete saturation of the mineral soil) was insufficient and the water table reached into the organic layer or that other factors not accounted for in the model played an important role in the initiation of these landslides.

Sensitivity analysis showed that on all landslides slope stability was mainly controlled by slope angle, soil cohesion and internal friction angle. By considering above-ground biomass separate from below-ground biomass and from the mass of mineral soil, we were able to show that an important influence of vegetation on slope stability is its contribution to the mass of the organic layer. This mass has a destabilizing effect above a minimum slope angle $\left(\alpha^{\text {crit. }}=37.9^{\circ} \pm 0.9^{\circ}\right)$. Slopes at least that steep characterize $31-36 \%$ of the entire study area. The critical angle beyond which the destabilizing effect of both soil and vegetation outweighs the stabilizing effects depends on other model parameters that control stability. Thus a transfer of these results to other sites requires recalculation on the basis of local soil shear strength and root cohesion measurements.

Above-ground biomass often is assumed to be negligible compared to the mass of the soil root system (O'Loughlin, 1974). Distinguishing the mass of mineral soil from the organic layer, we were able to show that on shallower landslides a major part of the sliding mass consisted of organic matter. Without making this distinction, the influence of vegetation would have been underestimated by a factor of about 10 .

While the size and frequency of landslides are considered to provide conditions for the outstandingly high levels of plant biodiversity at our research site (Connell, 1978; Sheil and Burslem, 2003; Lozano et al., 2005; Köhler and Huth, 2007; Bussmann et al., 2008), we found support for the idea of a biotic control on shallow translational landslides due to the increasingly destabilizing effect of the growing mass of the organic layer (up to 973 t ha $^{-1}$ under wet conditions). This implies a self-organization of biodiversity through a feedback mechanism between biotic and abiotic processes which is worth further investigation and contributes to our understanding of the interaction between landslides and plant diversity in similar environments. In its current form, the model is applicable in environments where steep slopes are covered by massive organic layers that accommodate the majority of roots. This situation is present in most tropical montane forests (Prandini et al., 1977).

Acknowledgements - This work has been conducted within the research group DFG-FOR 816 (Biodiversity and Sustainable Management of a Megadiverse Mountain Ecosystem in South Ecuador), funded by the German research foundation DFG (grant nos. EL255/7-1 and SCHR1000/4.2). We especially wish to thank Dave Milledge and Stephen Rice for their constructive comments that helped us very much to shape this article. 


\section{References}

Abernethy B, Rutherfurd ID. 2001. The distribution and strength of riparian tree roots in relation to riverbank reinforcement. Hydrological Processes 15: 63-79.

Anderson MG, Howes S. 1985. Development and application of a combined soil water-slope stability model. Quarterly Journal of Engineering Geology \& Hydrogeology 18: 225-236.

Beck E, Makeschin F, Haubrich F, Richter M, Bendix J, Valerezo C. 2008. The ecosystem (Reserva Biológica San Francisco). In Gradients in a Tropical Mountain Ecosystem of Ecuador, Caldwell M, Heldmaier G, Jackson R, Lange O, Mooney H, Schulze E-D, Sommer U, Beck E, Bendix J, Kottke I, Makeschin F, Mosandl R (eds). Springer: Berlin; 1-13.

Brown S. 1997. Estimating biomass and biomass change of tropical forests: a primer. FAO Forestry papers, Vol. 134, FAO, Rome.

Brown S, Gillespie AJR, Lugo AE. 1989. Biomass estimation methods for tropical forests with applications to forest inventory data. Forest Science 35: 881-902.

Buchanan P, Savigny KW. 1990. Factors controlling debris avalanche initiation. Canadian Geotechnical Journal 27: 659-675.

Bussmann RW, Wilke W, Richter M. 2008. Landslides as important disturbance regimes: causes and regeneration. In Gradients in a Tropical Mountain Ecosystem of Ecuador, Caldwell M, Heldmaier G, Jackson R, Lange O, Mooney H, Schulze E-D, Sommer U, Beck E, Bendix J, Kottke I, Makeschin F, Mosandl R (eds). Springer: Berlin; 319-330.

Casadei M, Dietrich WE, Miller N. 2003. Controls on shallow landslide size. In Debris-Flow Hazards Mitigation: Mechanics, Prediction, and Assessment, Vols $\mathbf{1}$ and 2, Rickenmann D, Chen C (eds). Millpress: Rotterdam; 91-101.

Collison AJC, Anderson MG. 1996. Using a combined slope hydrology/ stability model to identify suitable conditions for landslide prevention by vegetation in the humid tropics. Earth Surface Processes and Landforms 21: 737-747.

Comino E, Duretta A. 2009. In situ shear tests of soil samples with grass roots in alpine environment. American Journal of Environmental Sciences 5: 474-485.

Connell JH. 1978. Diversity in tropical rain forests and coral reefs. Science 199: 1302-1310.

De Baets S, Poesen J, Reubens B, Wemans K, Baerdemaeker JD, Muys B. 2008. Root tensile strength and root distribution of typical Mediterranean plant species and their contribution to soil shear strength. Plant and Soil 305: 207-226.

Dislich C, Günter S, Homeier J, Schröder B, Huth A. 2009. Simulating forest dynamics of a tropical montane forest in South Ecuador. Erdkunde 63: 347-364.

Gabet EJ, Dunne T. 2002. Landslides on coastal sage-scrub and grassland hillslopes in a severe El Niño winter: the effects of vegetation conversion on sediment delivery. Geological Society of America Bulletin 114: 983-990.

Guitierres F, Soldati M, Audemard F, Balteanu D. 2010. Recent advances in landslide investigation: issues and perspectives. Geomorphology 124: 95-101.

Guzzetti F. 2004. Book review of 'Catastrophic Landslides: Effects, Occurrence, and Mechanisms. Natural Hazards and Earth System Sciences 4: 531-531.

Guzzetti F, Carrara A, Cardinali M, Reichenbach P. 1999. Landslide hazard evaluation: a review of current techniques and their application in a multi-scale study, central Italy. Geomorphology 31: 181-216.

Jahn R, Blume H-P, Asio VB, Spaargaren O, Schad P. 2006. Guidelines for Soil Description, 4th edn. FAO: Rome.

Keim RF, Skaugset AE. 2003. Modelling effects of forest canopies on slope stability. Hydrological Processes 17: 1457-1467.

Köhler P, Huth A. 2007. Impacts of recruitment limitation and canopy disturbance on tropical tree species richness. Ecological Modelling 203: 511-517.

Leuschner C, Moser G, Bertsch C, Röderstein M, Hertel D. 2007. Large altitudinal increase in tree root/shoot ratio in tropical mountain forests of Ecuador. Basic and Applied Ecology 8: 219-230.
Lozano P, Bussmann RW, Küppers M. 2005. Landslides as ecosystem disturbance: their implications and importance in south Ecuador. Lyonia 8: 67-72.

Montgomery DR, Dietrich WE. 1994. A physically based model for the topographic control on shallow landsliding. Water Resources Research 30: 1153-1171.

Moser G, Röderstein M, Soethe N, Hertel D, Leuschner C. 2008. Altitudinal changes in stand structure and biomass allocation of tropical mountain forests in relation to microclimate and soil chemistry. In Gradients in a Tropical Mountain Ecosystem of Ecuador, Caldwell M, Heldmaier G, Jackson R, Lange O, Mooney H, Schulze E-D, Sommer U, Beck E, Bendix J, Kottke I, Makeschin F, Mosandl R (eds). Springer: Berlin; 229-242.

Muenchow J, Brenning A, Richter M. 2012. Geomorphic process rates of landslides along a humidity gradient in the tropical Andes. Geomorphology 139-140: 271-284.

Nogueira EM, Fearnside PM, Nelson BW. 2008. Normalization of wood density in biomass estimates of Amazon forests. Forest Ecology and Management 256: 990-996.

Oesker M, Dalitz H, Günter S, Homeier J, Matezki S. 2008. Spatial heterogeneity patterns: a comparison between gorges and ridges in the upper part of an evergreen lower montane forest. In Gradients in a Tropical Mountain Ecosystem of Ecuador, Beck E, Bendix J, Kottke I, Makeschin F, Mosandl R (eds). Springer: Berlin; 267-274.

O'Loughlin C. 1974. The effect of timber removal on the stability of forest soils. Journal of Hydrology (New Zealand) 13: 121-134.

Prandini L, Guidicini G, Bottura JA, Poncano WL, Santos AR. 1977. Behaviour of the vegetation in slope stability: a critical review. Bulletin of the International Association of Engineering Geology 16: 51-55.

Restrepo C, Walker LR, Shiels AB, Bussmann R, Claessens SLF, Lozano P, Negi G, Paolini GLP, Ramos-Scharr'on C, Richter M, Valzquez E. 2009. Landsliding and its multi-scale influence on mountainscapes. BioScience 59: 685-698.

Richter M, Diertl K, Emck P, Peters T, Beck E. 2009. Reasons for an outstanding plant diversity in the tropical Andes of southern Ecuador. Landscape Online 12: 1-35.

Schmidt KM, Roering JJ, Stock JD, Dietrich WE, Montgomery DR, Schaub T. 2001. The variability of root cohesion as an influence on shallow landslide susceptibility in the Oregon Coast Range. Canadian Geotechnical Journal 38: 995-1024.

Sheil D, Burslem DFRDP. 2003. Disturbing hypotheses in tropical forests. Trends in Ecology \& Evolution 18: 18-26.

Sidle RC, Dhakal AS. 2003. Recent advances in the spatial and temporal modeling of shallow landslides. In MODSIM 2003: International Congress on Modelling and Simulation, Canberra, Australia; 602-607.

Sidle RC, Ochiai H. 2006. Landslides: Processes, Prediction and Land Use. American Geophysical Union: Washington, DC.

Sidle RC, Wu W. 1999. Simulating effects of timber harvesting on the temporal and spatial distribution of shallow landslides. Zeitschrift für Geomorphologie 43: 185-201.

Soethe N, Lehmann J, Engels C. 2006a. Root morphology and anchorage of six native tree species from a tropical montane forest and an elfin forest in Ecuador. Plant and Soil 279: 173-185.

Soethe N, Lehmann J, Engels C. 2006b. The vertical pattern of rooting and nutrient uptake at different altitudes of a south Ecuadorian montane forest. Plant and Soil 286: 287-299.

Stoyan R. 2000. Aktivität, Ursachen und Klassifikation der Rutschungen in San Francisco/Süd Ecuador. Diploma thesis, University of ErlangenNuremberg, Germany.

Suzuki E. 1999. Diversity in specific gravity and water content of wood among Bornean tropical rainforest trees. Ecological Research 14: 211-224.

van Beek LPH, Wint J, Cammeraat LH, Edwards JP. 2005. Observation and simulation of root reinforcement on abandoned Mediterranean slopes. Plant and Soil 278: 55-74.

Vorpahl P, Elsenbeer H, Märker M, Schröder B. 2012. How can statistical models help to determine driving factors of landslides? Ecological Modelling 239: 27-39. 
Wilcke W, Yasin S, Abramowski U, Valarezo C, Zech W. 2002. Nutrient storage and turnover in organic layers under tropical montane rain forest in Ecuador. European Journal of Soil Science 53: 15-27.

Wu TH, McKinnell WPI, Swanston DN. 1979. Strength of tree roots and landslides on Prince of Wales Island, Alaska. Canadian Geotechnical Journal 16: 19-33.

Wu TH, Beal PE, Lan C. 1988a. In-situ shear test of soil-root systems. Journal of Geotechnical Engineering 114: 1376-1394.
Wu TH, McOmber RM, Erb RT, Beal PE. 1988b. Study of soilroot interaction. Journal of Geotechnical Engineering 114 1351-1375.

Wu W, Sidle RC. 1995. A distributed slope stability model for steep forested basins. Water Resources Research 31: 2097-2110.

Zimmermann B, Elsenbeer H. 2008. Spatial and temporal variability of soil saturated hydraulic conductivity in gradients of disturbance. Journal of Hydrology 30: 78-95. 